Supporting Information for

\title{
Conjugated or Broken: the Introduction of Isolation Spacer ahead of the Anchoring Moiety, and the Improved Device Performance
}

Zhaofei Chai ${ }^{\dagger}$, Sushu $\mathrm{Wan}^{\dagger}$, Cheng Zhong ${ }^{\dagger}$, Ting $\mathrm{Xu}^{\dagger}$, Manman Fang ${ }^{\dagger}$, Jinfeng Wang ${ }^{\dagger}$, Yujun Xie ${ }^{\dagger}$, Yu Zhang ${ }^{\dagger}$, Anyi Mei ${ }^{\ddagger}$, Hongwei Han ${ }^{\ddagger}$, Qian Peng ${ }^{\S}$, Qianqian $\mathrm{Li}^{* \dagger}$, and Zhen $\mathrm{Li}^{\dagger}{ }^{\dagger}$

${ }^{\dagger}$ Department of Chemistry, Hubei Key Lab on Organic and Polymeric Opto-Electronic Materials, Wuhan University, Wuhan 430072, China

${ }^{\ddagger}$ Michael Grätzel Center for Mesoscopic Solar Cells, Wuhan National Laboratory for Optoelectronics, Huazhong University of Science and Technology, Wuhan,430072, China.

${ }^{\S}$ Key Laboratory of Organic Solids, Beijing National Laboratory for Molecular Science, Institute of Chemistry, Chinese Academy of Sciences, Beijing, 100190, China.

Corresponding author. E-mail: qianqian-alinda@163.com (Q. Li); lizhen@whu.edu.cn or lichemlab@163.com (Z.Li). 


\section{Table of Contents}

\section{Additional data and analysis}

Chart S1. Some selected examples of coupled and decoupled systems

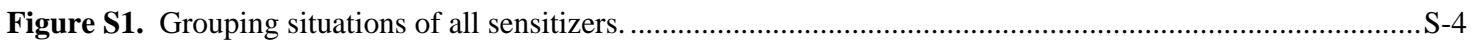

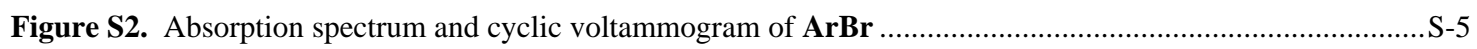

Figure S3. Optimized structures and dihedral angles between BTD and rIS ....................................................

Figure S4. Charge transfer resistance at the $\mathrm{TiO}_{2}$ /electrolyte interface ....................................................... -6

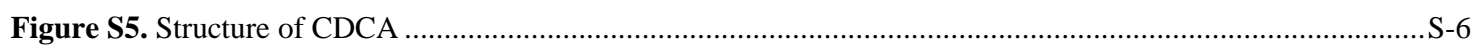

Figure S6. $J$ - $V$ characteristic curves of LI-87/CDCA and LI-90/CDCA co-adsorbed solar cells ......................... S-7

Figure S7. Comparison of the CE based on LI-87/CDCA and LI-90/CDCA sensitized solar cells.....................S-8

Table S1. Photovoltaic performances of DSCs based on LI-87/CDCA and LI-90/CDCA..................................8

2. Experimental details

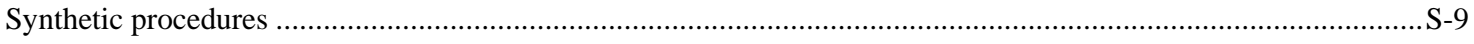

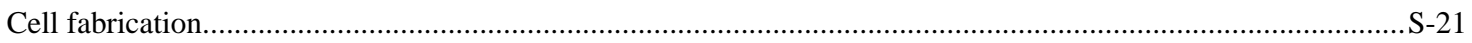

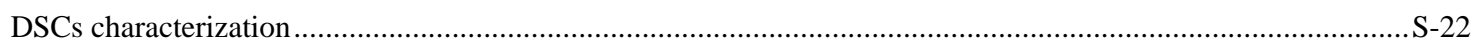

3. Reference 


\section{Additional data and analysis}

Chart S1. Some selected examples of coupled and decoupled systems.

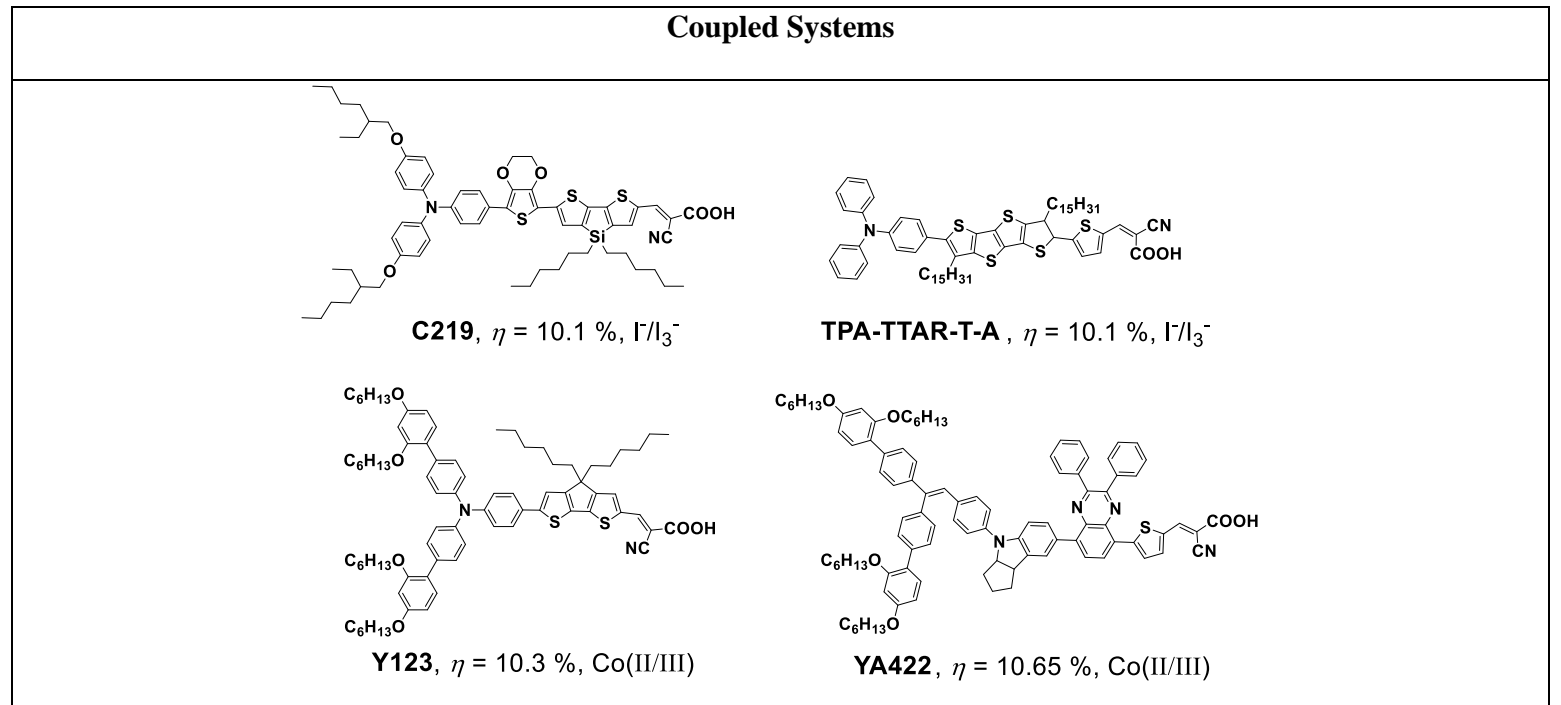

C219 $^{1}$, TPA-TTAR-T-A ${ }^{2}$ and $\mathbf{Y 1 2 3}^{3}$ used cyanoacetic acid as acceptor and anchoring group, which pull the LUMO orbitals to the vicinity of $\mathrm{TiO}_{2}$, and then enhance the electronic communication between the excited dyes and the semiconductor. For $\mathbf{Y A 4 4}^{4}$, the auxiliary acceptor and cyanoacetic acid was isolated by thienyl unit with small steric hindrance, ensuring a good co-planarity of the acceptor part, which also resulted in good electronic interaction with $\mathrm{TiO}_{2}$.

Decoupled Systems
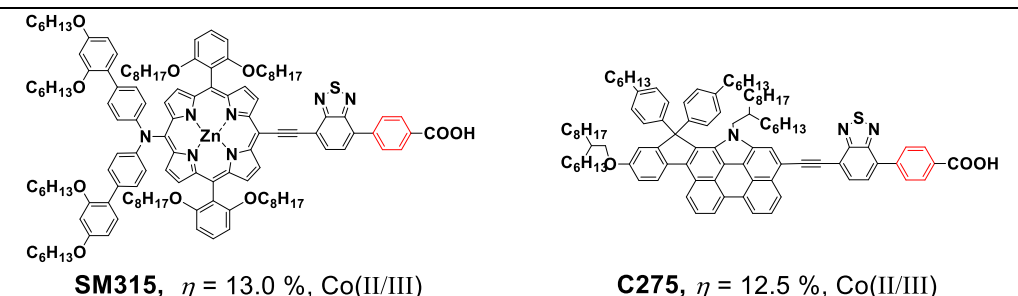

SM315, $\eta=13.0 \%, \mathrm{Co}(\mathrm{II} / \mathrm{III})$

C275, $\eta=12.5 \%, \mathrm{Co}(\mathrm{II} / \mathrm{III})$
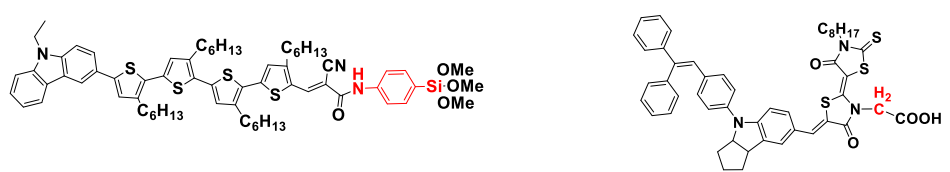

ADEKA1, $\eta=12.5 \%, \mathrm{Co}(\mathrm{II} / \mathrm{III})$

D205, $\eta=9.52 \%, \mathrm{I}^{-} / \mathrm{I}^{-}$

The light-harvesting parts/main acceptors of $\mathbf{S M 3 1 5}^{\mathbf{5}}, \mathbf{C 2 7 5}^{\mathbf{6}}$ and ADEKA1 ${ }^{\mathbf{7}}$ were isolated from anchoring group by phenyl or phenyl amino groups. For $\mathbf{D 2 0 5}^{\mathbf{8}}$, the conjugation was even broken by $-\mathrm{CH}_{2}$ - unit. 


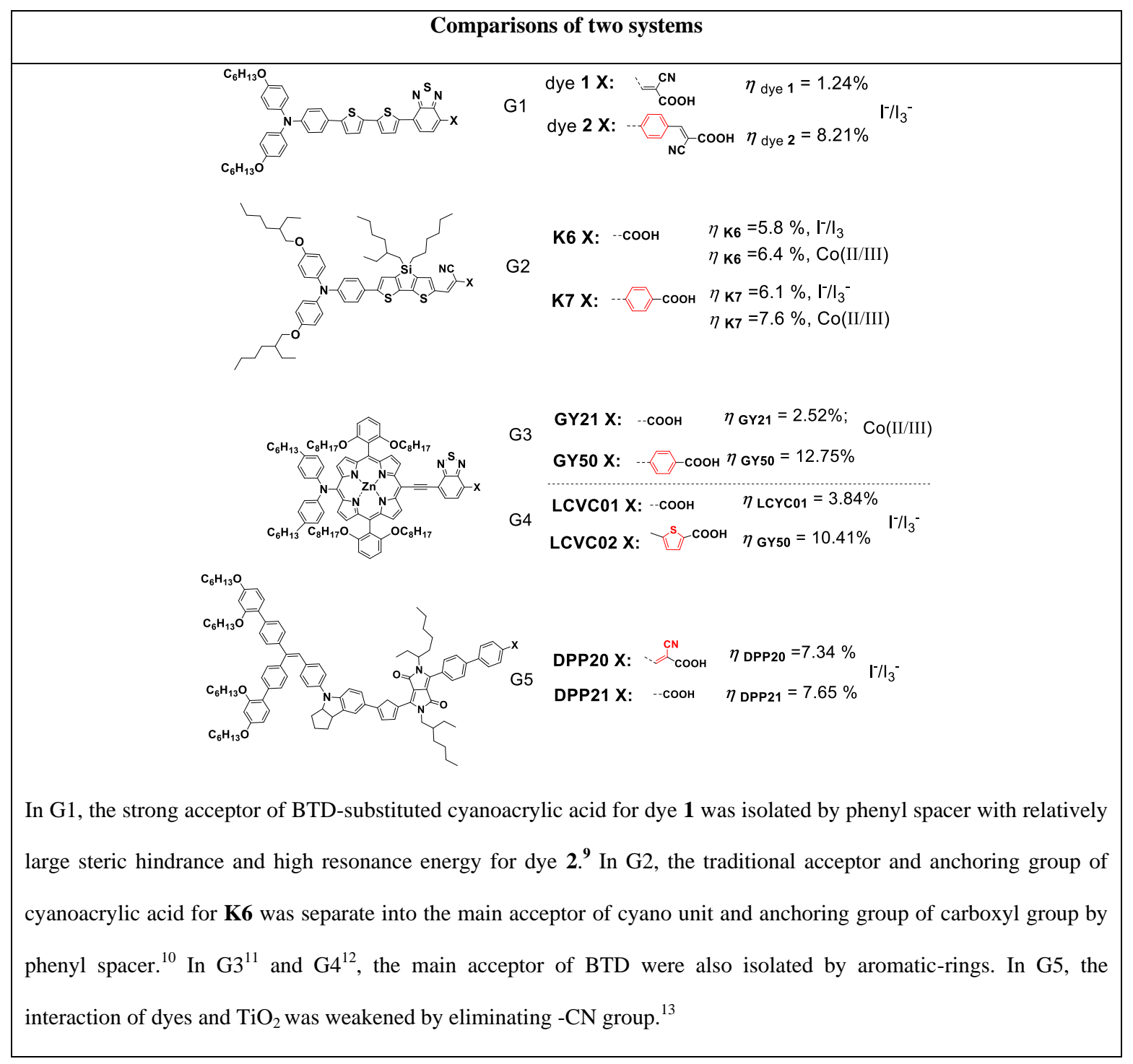

(a)

Figure S1. Grouping situations of all sensitizers. 

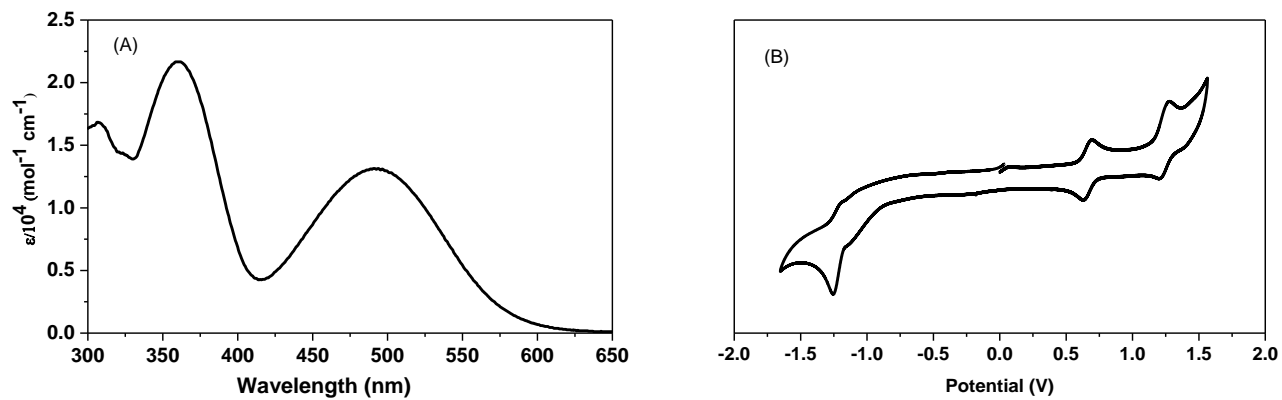

Figure S2. (A) Absorption spectrum and (B) cyclic voltammogram of $\mathbf{A r B r}$ in $\mathrm{CH}_{2} \mathrm{Cl}_{2}$ solution (concentration: $3 \times 10^{-5}$ $\mathrm{mol} / \mathrm{L})$.

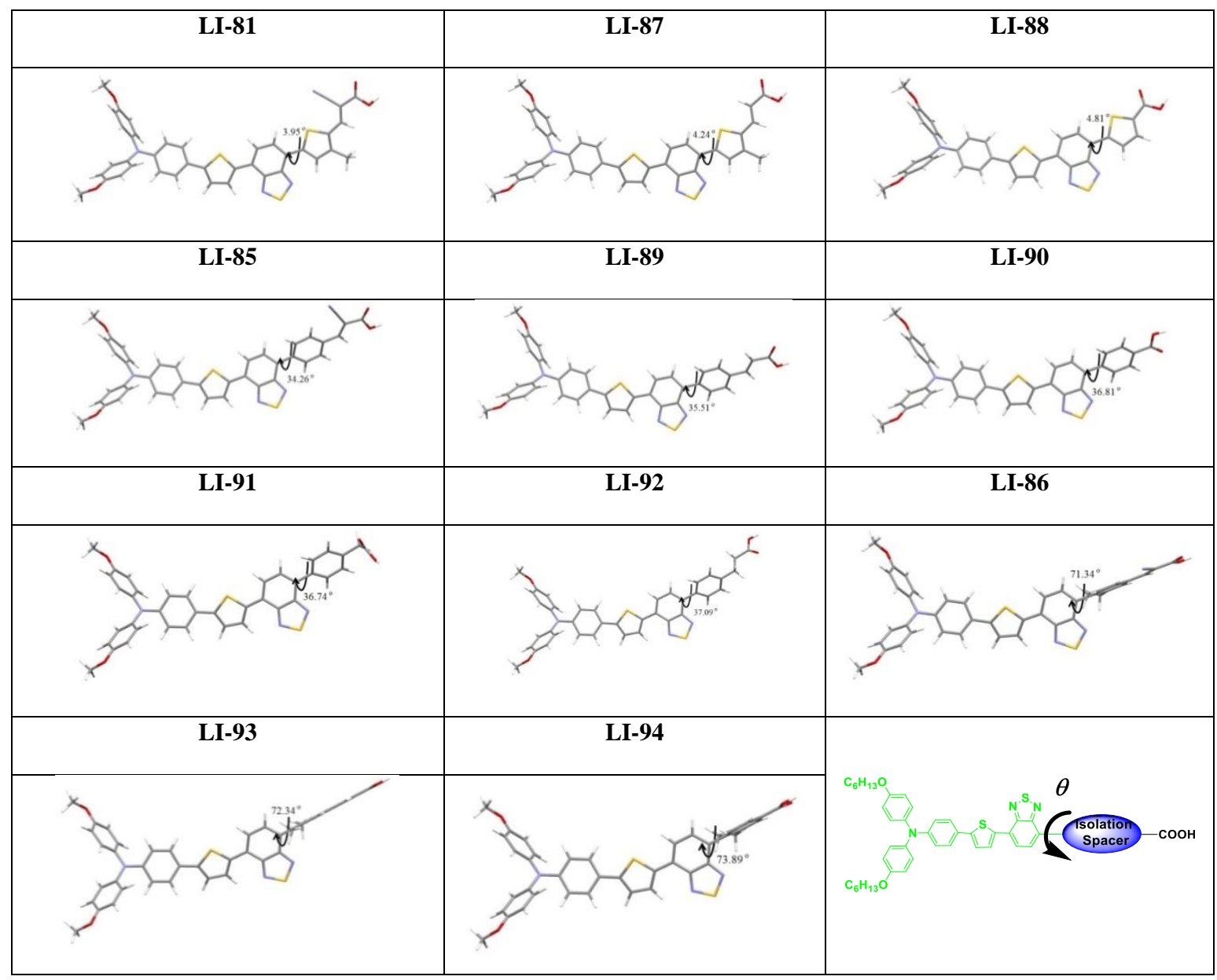

Figure S3. Optimized structures and dihedral angles between BTD and rIS. The long hexyloxyl substituent was replaced by a methoxyl moiety. 


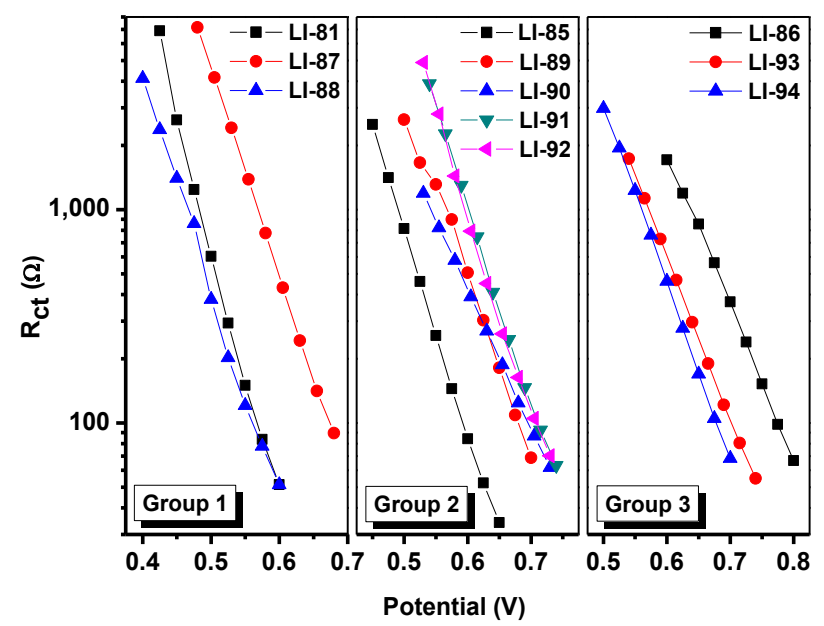

Figure S4. Charge transfer resistance at the $\mathrm{TiO}_{2} /$ electrolyte interface measured by EIS in the dark on the complete cells.

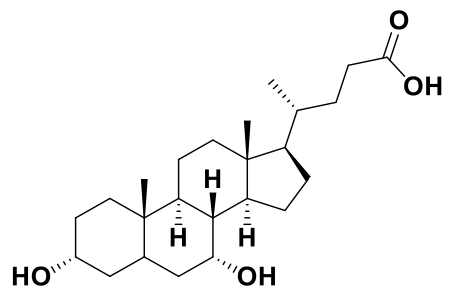

Figure S5. Structure of CDCA. 

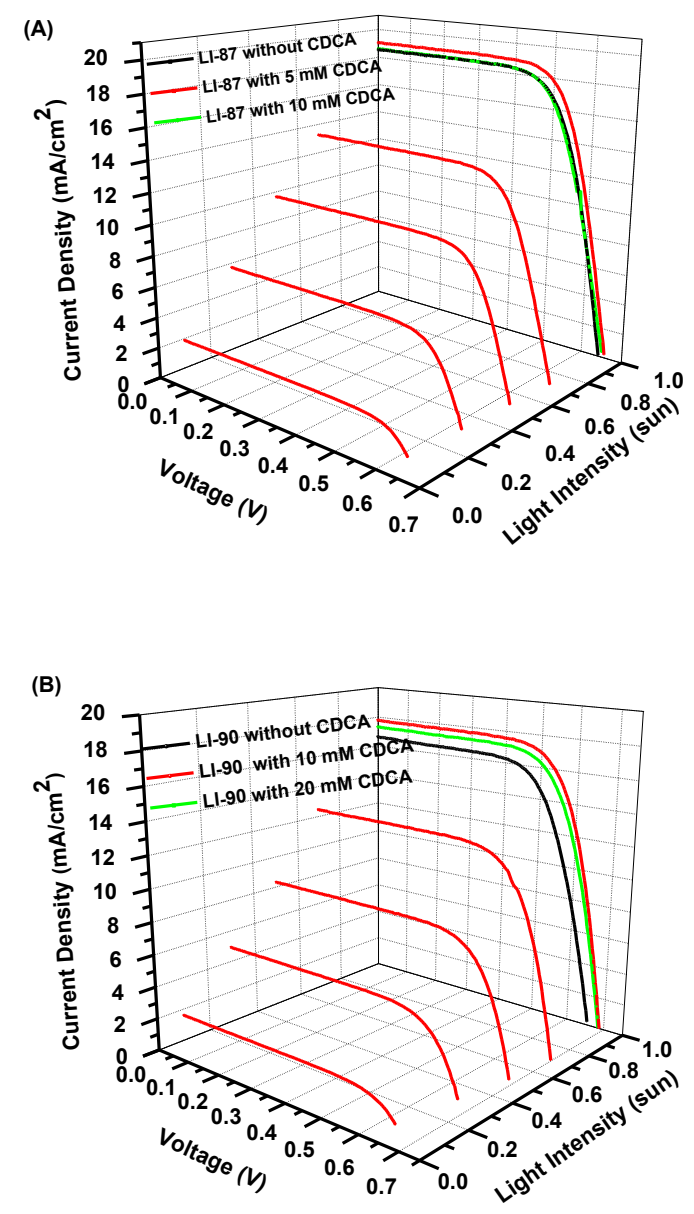

Figure S6. $J-V$ characteristic curves of LI-87/CDCA (A) and LI-90/CDCA (B) co-adsorbed cells under different light intensities. 

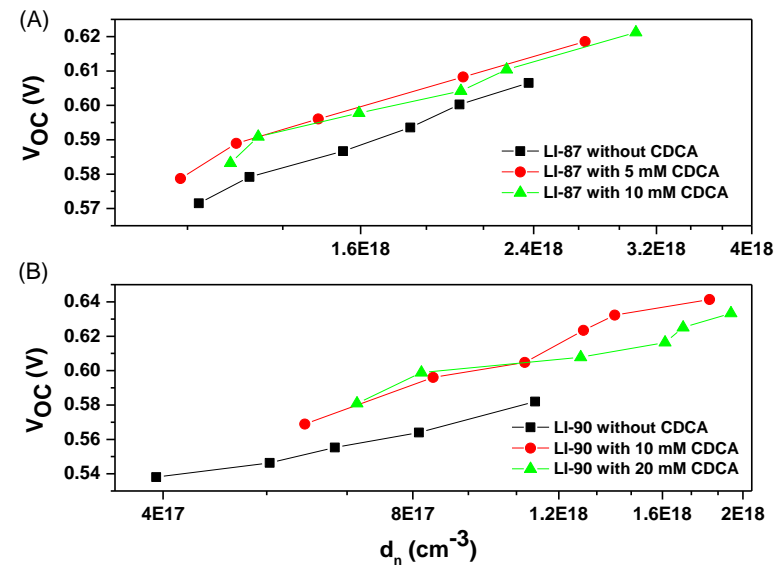

Figure S7. Comparison of the charges extracted from cells based on LI-87 (A) and LI-90 (B) with different amount of CDCA at a certain open-circuit photovoltage.

Table S1. Photovoltaic performance of DSCs based on LI-87/CDCA and LI-90/CDCA and best devices for each dye under different light intensity.

\begin{tabular}{|c|c|c|c|c|c|c|}
\hline $\begin{array}{c}I_{0} \\
\text { (sun) }\end{array}$ & Dye & CDCA & $\begin{array}{c}J_{\mathrm{SC}} \\
\left(\mathrm{mA} \mathrm{cm}^{-2}\right)\end{array}$ & $\begin{array}{l}V_{\mathrm{OC}} \\
(\mathrm{V})\end{array}$ & $\mathrm{FF}$ & $\begin{array}{c}\eta \\
(\%)\end{array}$ \\
\hline \multirow{6}{*}{0.996} & & 0 & 18.50 & 642 & 0.70 & 8.26 \\
\hline & LI-87 & 5 & 19.05 & 658 & 0.72 & 9.07 \\
\hline & & 10 & 18.62 & 652 & 0.71 & 8.66 \\
\hline & & 0 & 16.63 & 658 & 0.67 & 7.32 \\
\hline & LI-90 & 10 & 17.78 & 682 & 0.71 & 8.60 \\
\hline & & 20 & 17.32 & 687 & 0.71 & 8.44 \\
\hline \multirow{2}{*}{0.701} & LI-87 & 5 & 13.27 & 652 & 0.72 & 8.85 \\
\hline & LI-90 & 10 & 12.45 & 698 & 0.72 & 8.91 \\
\hline \multirow{2}{*}{0.496} & LI-87 & 5 & 9.64 & 648 & 0.75 & 9.36 \\
\hline & LI-90 & 10 & 8.31 & 690 & 0.73 & 8.41 \\
\hline \multirow{2}{*}{0.301} & LI-87 & 5 & 5.68 & 635 & 0.76 & 9.10 \\
\hline & LI-90 & 10 & 4.89 & 669 & 0.74 & 8.11 \\
\hline \multirow{2}{*}{0.099} & LI-87 & 5 & 1.84 & 618 & 0.77 & 8.73 \\
\hline & LI-90 & 10 & 1.59 & 630 & 0.74 & 7.43 \\
\hline
\end{tabular}




\section{Experimental details}

Instrumentation: ${ }^{1} \mathrm{H}$ NMR and ${ }^{13} \mathrm{C}$ NMR spectroscopy were recorded on a Varian Mercury 300 spectrometer using tetramethylsilane (TMS; $\delta=0 \mathrm{ppm}$ ) as internal standard. MS (MALDI-TOF) spectra were recorded on a Waters Micromass LCT Premier XE. Elemental analyses were performed by a 73 CARLOERBA-1106 micro-elemental analyzer. UV-visible spectra were obtained using a Shimadzu UV-2700 spectrometer. Fluorescence spectra were determined with a Hitachi F-4600 spectrometer. Cyclic voltammograms were carried out on a CHI660E electrochemical workstation at room temperature in nitrogen-purged anhydrous dichloromethane with tetrabutylammonium hexafluorophosphate $\left(\mathrm{TBAPF}_{6}\right)$ as the supporting electrolyte at a scanning rate of $100 \mathrm{mV} \mathrm{s}^{-1} . \mathrm{A}$ platinum disk and a $\mathrm{Ag} / \mathrm{AgCl}$ electrode were used as the working electrode and quasi-reference electrode, respectively. The ferrocene was used as the internal reference for calibration.

Materials: All solvents used were purified by standard procedures, or purged with nitrogen before use. Compound 1, 6, 7, 8, 9, 10 reagents were purchased and used directly as received. 4-bromo-3,5-dimethylbenzoic acid (compound 2) and $\mathrm{PhP}_{3}=\mathrm{CHCOOEt}^{16}$ were prepared according to modified procedures in the literature. Ar-Br, 4-bromo-3,5dimethylbenzaldehyde (compound 4) and 5-(7-(5-(4-(bis(4-(hexyloxy)phenyl) amino)phenyl)thiophen-2yl)benzo[c][1,2,5]thiadiazol-4-yl)-3-hexylthiophene-2-carbaldehyde (compound 17) were synthesized following our previously reported work. ${ }^{14}$ 
Synthetic procedures

Synthetic routes of sensitizers.

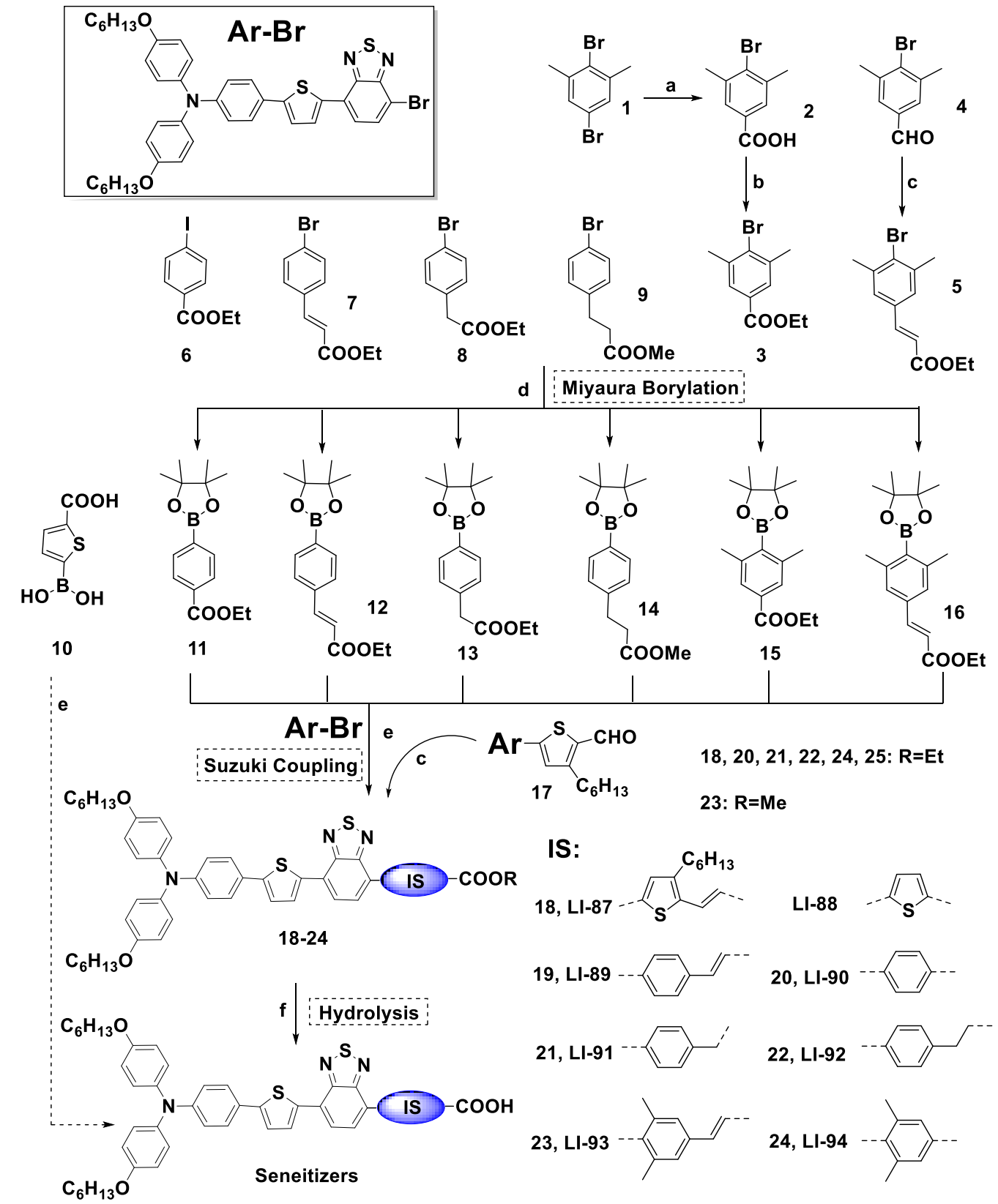

4-bromo-3, 5-dimethylbenzoic acid (compound 2)<smiles>Cc1cc(C(=O)O)cc(C)c1Br</smiles> 
In a dried Schlenk tube was dissolved 2,5-dibromo-1,3-dimethylbenzene (1.90 g, $7.30 \mathrm{mmol})$ in THF (30 mL) under nitrogen., $n$-BuLi (1.65 M in hexane, $4.80 \mathrm{~mL}, 7.98 \mathrm{mmol}$ ) was added dropwise and the solution was stirred for $1 \mathrm{~h}$ at $78{ }^{\circ} \mathrm{C}$. Then the resulting solution was warmed to $-56{ }^{\circ} \mathrm{C}$ and a stream of $\mathrm{CO}_{2}$ was bubbled for $3 \mathrm{~h}$. The reaction mixture was allowed to slowly warm to room temperature and then poured into $\mathrm{HCl}$ solution $(1 \mathrm{M}, 100 \mathrm{~mL})$. (Caution: excess $\mathrm{CO}_{2}$ dissolved in solution will be released in temperature-rise period.) The mixture was extracted three times with $\mathrm{CH}_{2} \mathrm{Cl}_{2}$, and organic layer was collected and dried over anhydrous sodium sulfate. After removal of the solvent under reduced pressure, the crude product was purified by column chromatography on silica gel to yield compond $\mathbf{2}$ as a white solid $(1.61 \mathrm{~g}, 96.6 \%) .{ }^{1} \mathrm{H}$ NMR $\left(300 \mathrm{MHz}, \mathrm{CDCl}_{3}, \delta\right): 7.79$ (s, 2H, $\left.\mathrm{ArH}\right), 2.48\left(\mathrm{~s}, 6 \mathrm{H},-\mathrm{CH}_{3}\right.$.

\section{Ethyl 4-bromo-3, 5-dimethylbenzoate (compound 3)}

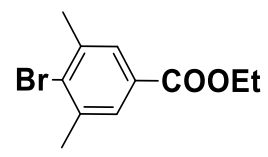

In a three-neck round-bottom flask was dissolved 4-bromo-3,5-dimethylbenzoic acid (4.90 g, $21.5 \mathrm{mmol})$ in ethanol $(60 \mathrm{~mL})$. Concentrated sulfuric acid $(2.0 \mathrm{~mL})$ was added to the reaction mixture and the reaction mixture was refluxed for $16 \mathrm{~h}$. Water was slowly added to quench the reaction and the solution was extracted with chloroform three times . Then the organic phase was washed with water and dried over anhydrous sodium sulfate. After solvent removal under reduced pressure, the crude product was purified by column chromatography to yield compound 3 as a white crystal compound.(3.42 g, 61.8\%).

${ }^{1} \mathrm{H}$ NMR $\left(300 \mathrm{MHz}, \mathrm{CDCl}_{3}, \delta\right): 7.73(\mathrm{~s}, 2 \mathrm{H}, \mathrm{ArH}), 4.36\left(\mathrm{q}, 2 \mathrm{H}, J=7.2 \mathrm{~Hz},-\mathrm{COOCH}_{2^{-}}\right), 2.46\left(\mathrm{~s}, 6 \mathrm{H},-\mathrm{CH}_{3}\right), 1.40(\mathrm{t}, 3 \mathrm{H}$, $\left.J=6.9 \mathrm{~Hz},-\mathrm{CH}_{3}\right)$.

\section{Ethyl (E)-3-(4-bromo-3,5-dimethylphenyl)acrylate (compound 5)}

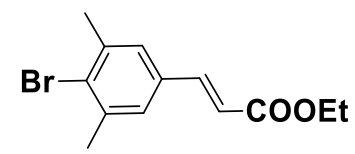

Compound 5 was obtained by Wittig reaction through addition of 4-bromo-3,5-dimethylbenzaldehyde and $\mathrm{PhP}_{3}=\mathrm{CHCOOEt}$.

Synthesis of Wittig reagent $\left(\mathrm{PhP}_{3}=\mathrm{CHCOOEt}\right)$ : In a round-bottomed flask were added ethyl 2-bromoacetate $(3.60 \mathrm{~mL}$, $32.46 \mathrm{mmol})$ and triphenylphosphine $(9.72 \mathrm{~g}, 37.06 \mathrm{mmol})$ in toluene $(10 \mathrm{~mL})$ at room temperature. The resulting 
mixture was stirred for $12 \mathrm{~h}$ at $80{ }^{\circ} \mathrm{C}$. After cooling to room temperature, the solvent was removed under reduced pressure to get a white solid. When the solid was dissolved in $\mathrm{CH}_{2} \mathrm{Cl}_{2}(100 \mathrm{~mL})$, the solution of $\mathrm{KOH}(4.00 \mathrm{~g}$ in 100 $\mathrm{mL}$ water) was added and stirred for another $1 \mathrm{~h}$. Then the $\mathrm{CH}_{2} \mathrm{Cl}_{2}$ layer was collected, and dried over anhydrous sodium sulfate. After solvent removal under reduced pressure, pale yellow crystals were formed and collected by filtration to give the desired Wittig reagent $(9.86 \mathrm{~g}, 87.2 \%)$, which could be stored in the dark at room temperature in a closed container.

Wittig reaction: In a round-bottomed flask were added 4-bromo-3,5-dimethylbenzaldehyde (500 mg, $2.35 \mathrm{mmol})$ and $\mathrm{PhP}_{3}=$ CHCOOEt $(3.27 \mathrm{~g}, 9.39 \mathrm{mmol})$ in anhydrous THF $(25 \mathrm{~mL})$. The reaction mixture was stirred for $48 \mathrm{~h}$ at room temperature. After solvent removal under reduced pressure, the crude product was purified by column chromatography on silica gel to yield compound 5 as a white solid $(661 \mathrm{mg}, 99.4 \%)$.

${ }^{1} \mathrm{H}$ NMR (300 MHz, $\left.\mathrm{CDCl}_{3}, \delta\right): 7.57(\mathrm{~d}, 1 \mathrm{H}, J=16.2 \mathrm{~Hz},=\mathrm{CH}), 7.23(\mathrm{~s}, 2 \mathrm{H}, \mathrm{ArH}), 6.41(\mathrm{~d}, 1 \mathrm{H}, J=16.2 \mathrm{~Hz},=\mathrm{CH})$, $4.27\left(\mathrm{q}, 2 \mathrm{H}, J=6.9 \mathrm{~Hz},-\mathrm{COOCH}_{2}-\right), 2.43\left(\mathrm{~s}, 6 \mathrm{H},-\mathrm{CH}_{3}\right), 1.33\left(\mathrm{t}, 3 \mathrm{H}, J=6.9 \mathrm{~Hz},-\mathrm{CH}_{3}\right)$.

\section{General procedures for Miyaura Borylation}

In a dried Schlenk tube were dissolved aromatic halides (1.0 equiv), bis(pinacolato)diboron (1.0 equiv), KOAc (3.0 equiv) and $\mathrm{Pd}(\mathrm{dppf}) \mathrm{Cl}_{2}\left(0.03\right.$ equiv) in $\mathrm{DMSO}$, which was degassed with nitrogen. The solution was stirred at $80{ }^{\circ} \mathrm{C}$ for $36 \mathrm{~h}$ to . Then the mixture was cooled to room temperature and water was added. The mixture was extracted with $\mathrm{CH}_{2} \mathrm{Cl}_{2}$ three times, and organic layer was collected and dried over anhydrous sodium sulfate. After removal of the solvent under reduced pressure, the crude product was purified by column chromatography on silica gel to obtain the desired product.

\section{Ethyl 4-(4,4,5,5-tetramethyl-1,3,2-dioxaborolan-2-yl)benzoate (compound 11)}

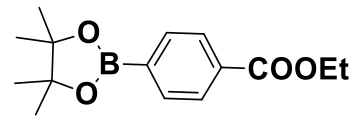

A colorless liquid was obtained as the desired product $(3.22 \mathrm{~g}, 80.5 \%)$.

${ }^{1} \mathrm{H}$ NMR (300 MHz, $\left.\mathrm{CDCl}_{3}, \delta\right): 8.03(\mathrm{~d}, 2 \mathrm{H}, J=7.5 \mathrm{~Hz}, \mathrm{ArH}), 7.87$ (d, 2H, $\left.J=7.8 \mathrm{~Hz}, \mathrm{ArH}\right), 4.38(\mathrm{q}, 2 \mathrm{H}, J=7.2 \mathrm{~Hz},-$ $\left.\mathrm{COOCH}_{2}-\right), 1.36\left(\mathrm{~m}, 15 \mathrm{H},-\mathrm{CH}_{3}\right)$.

Ethyl (E)-3-(4-(4,4,5,5-tetramethyl-1,3,2-dioxaborolan-2-yl)phenyl)acrylate (compound 12) 


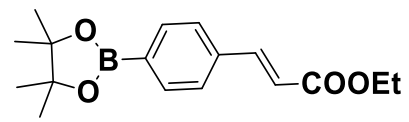

A colorless liquid was obtained as the desired product $(0.70 \mathrm{~g}, 32.3 \%)$.

${ }^{1} \mathrm{H}$ NMR (300 MHz, $\left.\mathrm{CDCl}_{3}, \delta\right): 7.82(\mathrm{~d}, 2 \mathrm{H}, J=7.8 \mathrm{~Hz}, \mathrm{ArH}), 7.64(\mathrm{~d}, 1 \mathrm{H}, J=15.9 \mathrm{~Hz},=\mathrm{CH}-), 7.52(\mathrm{~d}, 2 \mathrm{H}, J=7.2 \mathrm{~Hz}$, ArH), $6.49(\mathrm{~d}, 1 \mathrm{H}, J=16.2 \mathrm{~Hz},=\mathrm{CH}-), 4.26\left(\mathrm{q}, 2 \mathrm{H}, J=7.5 \mathrm{~Hz},-\mathrm{COOCH}_{2^{-}}\right), 1.33\left(\mathrm{~s}, \mathrm{br}, 15 \mathrm{H},-\mathrm{CH}_{3}\right)$.

Ethyl 2-(4-(4,4,5,5-tetramethyl-1,3,2-dioxaborolan-2-yl)phenyl)acetate (compound 13)

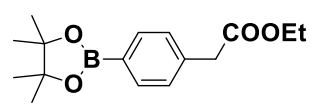

A colorless liquid was obtained as the desired product $(1.60 \mathrm{~g}, 67.0 \%)$.

${ }^{1} \mathrm{H}$ NMR (300 MHz, $\left.\mathrm{CDCl}_{3}, \delta\right): 7.77$ (d, 2H, $\left.J=7.8 \mathrm{~Hz}, \mathrm{ArH}\right), 7.30(\mathrm{~d}, 2 \mathrm{H}, J=7.5 \mathrm{~Hz}, \mathrm{ArH}), 4.13(\mathrm{q}, 2 \mathrm{H}, J=6.9 \mathrm{~Hz},-$ $\left.\mathrm{COOCH}_{2}-\right), 3.63\left(\mathrm{~s}, 2 \mathrm{H},-\mathrm{CH}_{2}-\right), 1.34\left(\mathrm{~s}, 12 \mathrm{H},-\mathrm{CH}_{3}\right), 1.24\left(\mathrm{t}, 3 \mathrm{H}, J=7.2 \mathrm{~Hz},-\mathrm{CH}_{3}\right)$.

Methyl 3-(4-(4,4,5,5-tetramethyl-1,3,2-dioxaborolan-2-yl)phenyl)propanoate (compound 14)

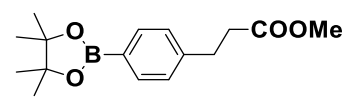

A white solid was obtained as the desired product (1.64 g, 68.8\%).

${ }^{1} \mathrm{H}$ NMR (300 MHz, $\left.\mathrm{CDCl}_{3}, \delta\right): 7.74(\mathrm{~d}, 2 \mathrm{H}, J=7.5 \mathrm{~Hz}, \mathrm{ArH}), 7.21(\mathrm{~d}, 2 \mathrm{H}, J=7.8 \mathrm{~Hz}, \mathrm{ArH}), 3.66\left(\mathrm{~s}, 3 \mathrm{H},-\mathrm{COOCH}_{3}\right)$, $2.97\left(\mathrm{t}, 2 \mathrm{H}, J=7.8 \mathrm{~Hz},-\mathrm{CH}_{2}-\right), 2.63\left(\mathrm{t}, 2 \mathrm{H}, J=8.1 \mathrm{~Hz},-\mathrm{CH}_{2}-\right), 1.34\left(\mathrm{~s}, 12 \mathrm{H},-\mathrm{CH}_{3}\right)$.

Ethyl 3,5-dimethyl-4-(4,4,5,5-tetramethyl-1,3,2-dioxaborolan-2-yl)benzoate (compound 15)

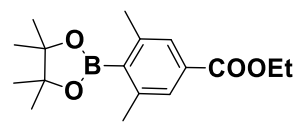

A colorless liquid was obtained as the desired product $(2.12 \mathrm{~g}, 59.7 \%)$.

${ }^{1} \mathrm{H}$ NMR (300 MHz, $\left.\mathrm{CDCl}_{3}, \delta\right): 7.61$ (s, 2H, ArH), 4.34 (q, 2H, J=6.9 Hz, - $\mathrm{COOCH}_{2}$ ), 2.43 (s, 6H, -CH $), 1.38(\mathrm{~s}, \mathrm{br}$, $\left.15 \mathrm{H},-\mathrm{CH}_{3}\right)$.

Ethyl (E)-3-(3,5-dimethyl-4-(4,4,5,5-tetramethyl-1,3,2-dioxaborolan-2-yl)phenyl)acrylate (compound 16) 


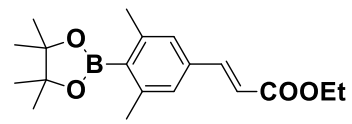

A pale yellow oil was obtained as the desired product (105 mg, 33.4\%).

${ }^{1} \mathrm{H}$ NMR (300 MHz, $\left.\mathrm{CDCl}_{3}, \delta\right): 7.60$ (d, 1H, $\left.J=16.2 \mathrm{~Hz},=\mathrm{CH}-\right), 7.11(\mathrm{~s}, 2 \mathrm{H}, \mathrm{ArH}), 6.42(\mathrm{~d}, 1 \mathrm{H}, J=15.9 \mathrm{~Hz},=\mathrm{CH}-)$, $4.24\left(\mathrm{q}, 2 \mathrm{H}, J=6.9 \mathrm{~Hz},-\mathrm{COOCH}_{2}-\right), 2.40\left(\mathrm{~s}, 6 \mathrm{H},-\mathrm{CH}_{3}\right), 1.39\left(\mathrm{~s}, 12 \mathrm{H},-\mathrm{CH}_{3}\right), 1.33\left(\mathrm{t}, 3 \mathrm{H}, J=6.9 \mathrm{~Hz},-\mathrm{CH}_{3}\right)$.

Ethyl (E)-3-(5-(7-(5-(4-(bis(4-(hexyloxy)phenyl)amino)phenyl)thiophen-2-yl)benzo[c][1,2,5]thiadiazol-4-yl)-3hexylthiophen-2-yl)acrylate (compound 18)

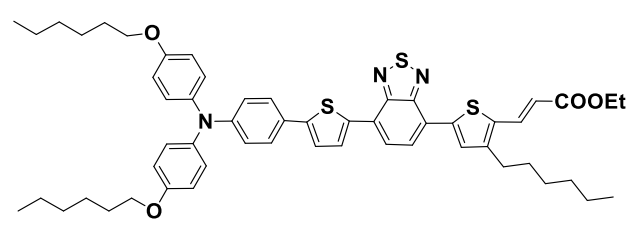

The synthesis of compound $\mathbf{1 8}$ followed the same conditions with that of compound $\mathbf{5}$. A dark red solid was obtained as the desired product $(123 \mathrm{mg}, 94.8 \%)$.

${ }^{1} \mathrm{H}$ NMR $\left(300 \mathrm{MHz}, \mathrm{CDCl}_{3}, \delta\right): 8.14(\mathrm{~d}, 1 \mathrm{H}, J=3.9 \mathrm{~Hz}, \mathrm{ArH}), 7.96-7.86(\mathrm{~m}, 4 \mathrm{H}, \mathrm{ArH}$ and $-\mathrm{CH}=), 7.50(\mathrm{~d}, 2 \mathrm{H}, J=8.7$ $\mathrm{Hz}, \mathrm{ArH}), 7.28(\mathrm{~d}, 1 \mathrm{H}, J=3.6 \mathrm{~Hz}, \mathrm{ArH}), 7.08(\mathrm{~d}, 4 \mathrm{H}, J=9.0 \mathrm{~Hz}, \mathrm{ArH}), 6.94(\mathrm{~d}, 2 \mathrm{H}, J=9.0 \mathrm{~Hz}, \mathrm{ArH}), 6.84(\mathrm{~d}, 4 \mathrm{H}, J=$ $8.4 \mathrm{~Hz}, \mathrm{ArH}), 6.30(\mathrm{~d}, 1 \mathrm{H}, J=15.3 \mathrm{~Hz},-\mathrm{CH}=), 4.27\left(\mathrm{q}, 2 \mathrm{H}, J=6.9 \mathrm{~Hz},-\mathrm{COOCH}_{2^{-}}\right), 3.94\left(\mathrm{t}, 4 \mathrm{H}, J=6.9 \mathrm{~Hz},-\mathrm{OCH}_{2^{-}}\right)$, $2.79\left(\mathrm{t}, 2 \mathrm{H}, J=7.8 \mathrm{~Hz},-\mathrm{CH}_{2^{-}}\right), 1.81-1.66\left(\mathrm{~m}, 6 \mathrm{H},-\mathrm{CH}_{2^{-}}\right), 1.47-1.35\left(\mathrm{~m}, 21 \mathrm{H},-\mathrm{CH}_{2^{-}},-\mathrm{CH}_{3}\right), 0.90\left(\mathrm{~m}, 9 \mathrm{H},-\mathrm{CH}_{3}\right)$.

\section{General procedures for Suzuki Coupling}

In a dried Schlenk tube were added $\mathrm{ArBr}$ (1.0 equiv), arylboronic acid (or borate) (1.5 equiv), $\mathrm{Pd}\left(\mathrm{PPh}_{3}\right)_{4},(0.05$ equiv), $\mathrm{K}_{2} \mathrm{CO}_{3}$ (5.0 equiv) in a solvent mixture of $\mathrm{THF} / \mathrm{H}_{2} \mathrm{O}(10 \mathrm{~mL}, 5 / 1, \mathrm{v} / \mathrm{v})$ under nitrogen. The reaction mixture was stirred at $80{ }^{\circ} \mathrm{C}$ for $16 \mathrm{~h}$ and then poured into water. The mixture was extracted three times with chloroform. The organic layer was collected and dried over anhydrous sodium sulfate. After removal of the solvent under reduced pressure, the crude product was purified by column chromatography on silica gel to obtain the desired product. 
yl)phenyl)acrylate (compound 19)

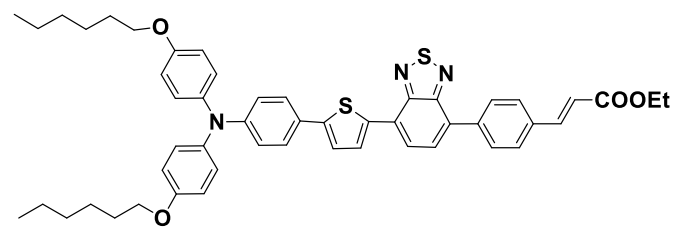

A red solid was obtained as the desired product (150 $\mathrm{mg}, 77.7 \%)$.

${ }^{1} \mathrm{H}$ NMR $\left(300 \mathrm{MHz}, \mathrm{CDCl}_{3}, \delta\right): 8.14(\mathrm{~d}, 1 \mathrm{H}, J=3.3 \mathrm{~Hz}, \mathrm{ArH}), 8.02(\mathrm{~d}, 2 \mathrm{H}, J=8.4 \mathrm{~Hz}, \mathrm{ArH}), 7.80-7.69$ (m, 4H, ArH and $=\mathrm{CH}-), 7.50(\mathrm{~d}, 2 \mathrm{H}, J=8.7 \mathrm{~Hz}, \mathrm{ArH}), 7.26(\mathrm{~s}, \mathrm{br}, 1 \mathrm{H}, \mathrm{ArH}), 7.08(\mathrm{~d}, 4 \mathrm{H}, J=8.1 \mathrm{~Hz}, \mathrm{ArH}), 6.94(\mathrm{~d}, 2 \mathrm{H}, J=7.2 \mathrm{~Hz}$, ArH), $6.84(\mathrm{~d}, 4 \mathrm{H}, J=8.7 \mathrm{~Hz}, \mathrm{ArH}), 6.53(\mathrm{~d}, 1 \mathrm{H}, J=15.9 \mathrm{~Hz},=\mathrm{CH}-), 4.29$ (q, 2H, $\left.J=6.9 \mathrm{~Hz},-\mathrm{COOCH}_{2}-\right), 3.95$ (t, $4 \mathrm{H}$, $\left.J=6.0 \mathrm{~Hz},-\mathrm{OCH}_{2}-\right), 1.79\left(\mathrm{~m}, 4 \mathrm{H},-\mathrm{CH}_{2}-\right), 1.47-1.35\left(\mathrm{~m}, 15 \mathrm{H},-\mathrm{CH}_{2^{-}}\right), 0.92\left(\mathrm{~s}, \mathrm{br}, 6 \mathrm{H},-\mathrm{CH}_{3}\right)$.

Ethyl 4-(7-(5-(4-(bis(4-(hexyloxy)phenyl)amino)phenyl)thiophen-2-yl)benzo[c][1,2,5]thiadiazol-4-yl)benzoate (compound 20)

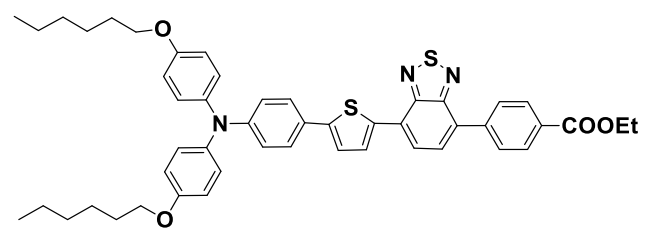

A dark red solid was obtained as the desired product (171 $\mathrm{mg}, 86.8 \%$ yield).

${ }^{1} \mathrm{H}$ NMR $\left(300 \mathrm{MHz}, \mathrm{CDCl}_{3}, \delta\right): 8.21(\mathrm{~d}, 2 \mathrm{H}, J=8.4 \mathrm{~Hz}, \mathrm{ArH}), 8.15(\mathrm{~d}, 1 \mathrm{H}, J=3.9 \mathrm{~Hz}, \mathrm{ArH}), 8.05(\mathrm{~d}, 2 \mathrm{H}, J=8.1 \mathrm{~Hz}$, ArH), $7.94(\mathrm{~d}, 1 \mathrm{H}, J=7.5 \mathrm{~Hz}, \operatorname{ArH}), 7.78(\mathrm{~d}, 1 \mathrm{H}, J=7.5 \mathrm{~Hz}, \mathrm{ArH}), 7.50(\mathrm{~d}, 2 \mathrm{H}, J=8.7 \mathrm{~Hz}, \mathrm{ArH}), 7.29$ (s, br, $1 \mathrm{H}$, $\operatorname{ArH}), 7.08(\mathrm{~d}, 4 \mathrm{H}, J=8.1 \mathrm{~Hz}, \operatorname{ArH}), 6.94(\mathrm{~d}, 2 \mathrm{H}, J=8.4 \mathrm{~Hz}, \operatorname{ArH}), 6.85(\mathrm{~d}, 4 \mathrm{H}, J=9.0 \mathrm{~Hz}, \operatorname{ArH}), 4.43(\mathrm{q}, 2 \mathrm{H}, J=6.9$ $\left.\mathrm{Hz},-\mathrm{COOCH}_{2}-\right), 3.95\left(\mathrm{t}, 4 \mathrm{H}, J=6.0 \mathrm{~Hz},-\mathrm{OCH}_{2^{-}}\right), 1.79\left(\mathrm{~m}, 4 \mathrm{H},-\mathrm{CH}_{2^{-}}\right), 1.41-1.35\left(\mathrm{~m}, 15 \mathrm{H},-\mathrm{CH}_{2^{-}},-\mathrm{CH}_{3}\right), 0.92(\mathrm{t}, 6 \mathrm{H}, J$ $\left.=6.3 \mathrm{~Hz},-\mathrm{CH}_{3}\right)$.

Ethyl 2-(4-(7-(5-(4-(bis(4-(hexyloxy)phenyl)amino)phenyl)thiophen-2-yl)benzo[c] $[1,2,5]$ thiadiazol-4yl)phenyl)acetate (compound 21) 


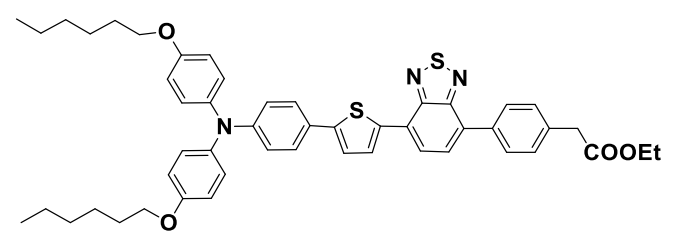

A red solid was obtained as the desired product (125 $\mathrm{mg}, 75.1 \%$ yield).

${ }^{1} \mathrm{H}$ NMR (300 MHz, $\left.\mathrm{CDCl}_{3}, \delta\right): 8.12(\mathrm{~d}, 1 \mathrm{H}, J=3.3 \mathrm{~Hz}, \mathrm{ArH}), 7.93(\mathrm{~m}, 3 \mathrm{H}, \mathrm{ArH}), 7.72(\mathrm{~d}, 1 \mathrm{H}, J=7.2 \mathrm{~Hz}, \mathrm{ArH}), 7.49$ (m, 4H, ArH), 7.26 (s, br, 1H, ArH), 7.07 (d, 4H, $J=8.1 \mathrm{~Hz}, \mathrm{ArH}), 6.94$ (d, 2H, $J=7.5 \mathrm{~Hz}, \operatorname{ArH}), 6.84(\mathrm{~d}, 4 \mathrm{H}, J=8.4$ $\mathrm{Hz}, \mathrm{ArH}), 4.18\left(\mathrm{q}, 2 \mathrm{H}, J=7.2 \mathrm{~Hz},-\mathrm{COOCH}_{2^{-}}\right), 3.94\left(\mathrm{~s}, \mathrm{br}, 4 \mathrm{H},-\mathrm{OCH}_{2^{-}}\right), 3.71\left(\mathrm{~s}, 2 \mathrm{H},-\mathrm{CH}_{2^{-}}\right), 1.79\left(\mathrm{~m}, 4 \mathrm{H},-\mathrm{CH}_{2^{-}}\right)$, $1.47-1.26\left(\mathrm{~m}, 15 \mathrm{H},-\mathrm{CH}_{2}-\right), 0.92\left(\mathrm{~s}, \mathrm{br}, 6 \mathrm{H},-\mathrm{CH}_{3}\right)$.

Methyl 3-(4-(7-(5-(4-(bis(4-(hexyloxy)phenyl)amino)phenyl)thiophen-2-yl)benzo[c][1,2,5]thiadiazol-4yl)phenyl)propanoate (compound 22)

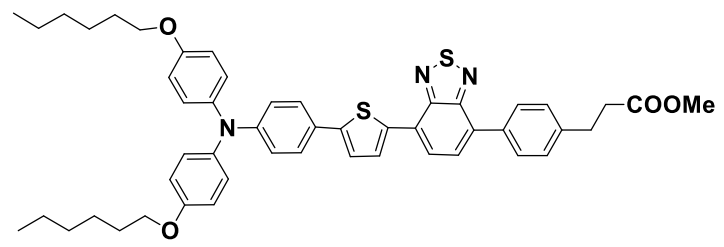

A red solid was obtained as the desired product (140 $\mathrm{mg}, 75.0 \%)$.

${ }^{1} \mathrm{H}$ NMR (300 MHz, $\left.\mathrm{CDCl}_{3}, \delta\right): 8.12(\mathrm{~d}, 1 \mathrm{H}, J=3.6 \mathrm{~Hz}, \mathrm{ArH}), 7.91(\mathrm{~m}, 3 \mathrm{H}, \mathrm{ArH}), 7.71(\mathrm{~d}, 1 \mathrm{H}, J=7.5 \mathrm{~Hz}, \mathrm{ArH}), 7.50$ $(\mathrm{d}, 2 \mathrm{H}, J=8.7 \mathrm{~Hz}, \operatorname{ArH}), 7.39(\mathrm{~d}, 2 \mathrm{H}, J=8.1 \mathrm{~Hz}, \operatorname{ArH}), 7.29(\mathrm{~d}, 1 \mathrm{H}, J=4.2 \mathrm{~Hz}, \operatorname{ArH}), 7.08(\mathrm{~d}, 4 \mathrm{H}, J=8.7 \mathrm{~Hz}, \mathrm{ArH})$, $6.94(\mathrm{~d}, 2 \mathrm{H}, J=8.1 \mathrm{~Hz}, \mathrm{ArH}), 6.84(\mathrm{~d}, 4 \mathrm{H}, J=8.4 \mathrm{~Hz}, \mathrm{ArH}), 3.94\left(\mathrm{t}, 4 \mathrm{H}, J=6.3 \mathrm{~Hz},-\mathrm{OCH}_{2}-\right), 3.71\left(\mathrm{~s}, 3 \mathrm{H},-\mathrm{COOCH}_{3}\right)$, $3.05\left(\mathrm{t}, 2 \mathrm{H}, J=7.5 \mathrm{~Hz},-\mathrm{CH}_{2^{-}}\right), 2.72\left(\mathrm{t}, 2 \mathrm{H}, J=8.1 \mathrm{~Hz},-\mathrm{CH}_{2^{-}}\right), 1.79\left(\mathrm{~m}, 4 \mathrm{H},-\mathrm{CH}_{2^{-}}\right), 1.46-1.34\left(\mathrm{~m}, 12 \mathrm{H},-\mathrm{CH}_{2^{-}}\right), 0.91(\mathrm{~s}$, br, $\left.6 \mathrm{H},-\mathrm{CH}_{3}\right)$.

Ethyl (E)-3-(4-(7-(5-(4-(bis(4-(hexyloxy)phenyl)amino)phenyl)thiophen-2-yl)benzo[c][1,2,5]thiadiazol-4-yl)-3,5dimethylphenyl)acrylate (compound 23)

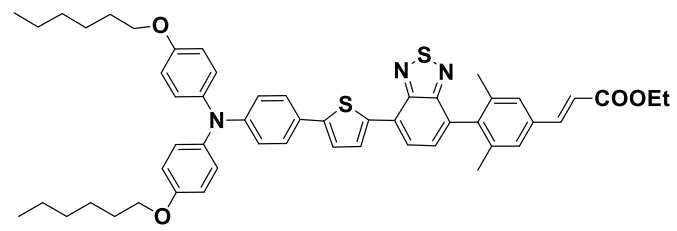

A dark red solid was obtained as the desired product (75 mg, 35.3\%). 
${ }^{1} \mathrm{H}$ NMR $\left(300 \mathrm{MHz}, \mathrm{DMSO}-d_{6}, \delta\right): 8.16(\mathrm{~m}, 2 \mathrm{H}, \mathrm{ArH}), 7.68-7.57(\mathrm{~m}, 6 \mathrm{H}, \mathrm{ArH}$ and $-\mathrm{CH}=), 7.49(\mathrm{~d}, 1 \mathrm{H}, J=3.6 \mathrm{~Hz}$, $\operatorname{ArH}), 7.05(\mathrm{~d}, 4 \mathrm{H}, J=8.4 \mathrm{~Hz}, \mathrm{ArH}), 6.92(\mathrm{~d}, 4 \mathrm{H}, J=8.1 \mathrm{~Hz}, \mathrm{ArH}), 6.81(\mathrm{~d}, 2 \mathrm{H}, J=8.1 \mathrm{~Hz}, \mathrm{ArH}), 6.68(\mathrm{~d}, 1 \mathrm{H}, J=15.6$ $\mathrm{Hz},=\mathrm{CH}-), 4.22\left(\mathrm{q}, 2 \mathrm{H}, J=7.5 \mathrm{~Hz},-\mathrm{COOCH}_{2}-\right), 3.94\left(\mathrm{t}, 4 \mathrm{H}, J=6.0 \mathrm{~Hz},-\mathrm{OCH}_{2}-\right), 1.95\left(\mathrm{~s}, 6 \mathrm{H},-\mathrm{CH}_{3}\right), 1.70(\mathrm{~m}, 4 \mathrm{H},-$ $\left.\mathrm{CH}_{2^{-}}\right), 1.41-1.28\left(\mathrm{~m}, 15 \mathrm{H},-\mathrm{CH}_{2}\right.$-and $\left.-\mathrm{CH}_{3}\right), 0.88\left(\mathrm{~s}, \mathrm{br}, 6 \mathrm{H},-\mathrm{CH}_{3}\right)$.

5-(7-(5-(4-(bis(4-(hexyloxy)phenyl)amino)phenyl)thiophen-2yl)benzo[c][1,2,5] thiadiazol-4-yl)thiophene-2carboxylic acid (LI-88)

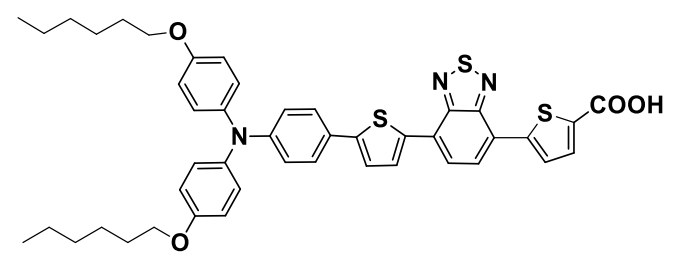

A dark red solid was obtained as the desired product (40 mg, 25.3\%).

${ }^{1} \mathrm{H}$ NMR (300 MHz, DMSO- $\left.d_{6}, \delta\right): 8.18-8.11(\mathrm{~m}, 4 \mathrm{H}, \mathrm{ArH}), 7.68$ (s, br, $\left.1 \mathrm{H}, \mathrm{ArH}\right), 7.57$ (d, 2H, $\left.J=8.4 \mathrm{~Hz}, \mathrm{ArH}\right), 7.50$ (s, br, 1H, ArH), 7.05 (d, 4H, J=7.2 Hz, ArH), 6.92 (d, 4H, J=8.4 Hz, ArH), 6.79 (d, 2H, J= 7.8 Hz, ArH), 3.94 (s, br, $\left.4 \mathrm{H},-\mathrm{OCH}_{2}-\right), 1.70\left(\mathrm{~m}, 4 \mathrm{H},-\mathrm{CH}_{2}-\right), 1.41-1.31\left(\mathrm{~m}, 12 \mathrm{H},-\mathrm{CH}_{2}-\right), 0.88\left(\mathrm{~s}, \mathrm{br}, 6 \mathrm{H},-\mathrm{CH}_{3}\right) .{ }^{13} \mathrm{C} \mathrm{NMR}\left(100 \mathrm{MHz}, \mathrm{CDCl}_{3}, \delta\right)$ : $155.50,153.61,152.61,148.61,146.28,140.25,136.46,133.46,133.97,129.29,129.04,128.85,128.54,128.19$, $127.70,126.92,126.61,126.31,126.14,124.64,122.48,120.10,115.18,68.13,31.56,29.62,25.71,22.54,13.97$. HRMS (ESI, m/z): $[\mathrm{M}+\mathrm{H}]^{+}$calcd for: $\mathrm{C}_{45} \mathrm{H}_{45} \mathrm{~N}_{3} \mathrm{O}_{4} \mathrm{~S}_{3}$, 788.2650; Found, 788.2648. Anal. Cald for $\mathrm{C}_{45} \mathrm{H}_{45} \mathrm{~N}_{3} \mathrm{O}_{4} \mathrm{~S}_{3}$ : C, 68.59; H, 5.76; N, 5.33; Found: C, 68.91; H, 5.98; N, 5.21.

\section{General procedures for hydrolysis}

In a round-bottomed flask equipped with a condenser pipe were dissolved ethyl or methyl ester (1.0 equiv) and $\mathrm{KOH}$ (10.0 equiv) in a solvent mixture of $\mathrm{THF} / \mathrm{H}_{2} \mathrm{O}(10 \mathrm{~mL}, 5 / 1, \mathrm{v} / \mathrm{v})$. The reaction mixture was refluxed for $12 \mathrm{~h}$ and then cooled to room temperature. After being washed with $0.1 \mathrm{M}$ hydrochloric acid and deionized water, the mixture was extracted with chloroform three times. The organic layer was collected and dried over anhydrous sodium sulfate. Then, after solvent removal under reduced pressure, the crude product was purified by column chromatography on silica gel to obtain the desired product. 
(E)-3-(5-(7-(5-(4-(bis(4-(hexyloxy)phenyl)amino)phenyl)thiophen-2-yl)benzo[c][1,2,5]thiadiazol-4-yl)-3hexylthiophen-2-yl)acrylic acid (LI-87)

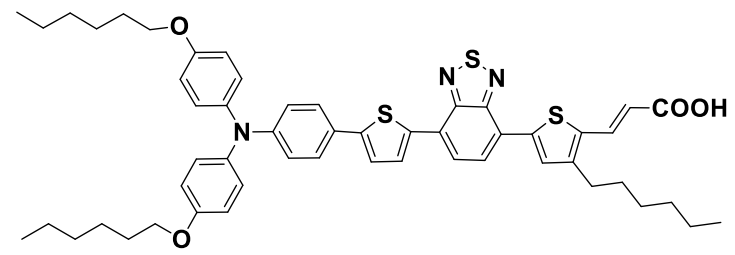

A dark red solid was obtained as the desired product (94 mg, 80.5\%).

${ }^{1} \mathrm{H}$ NMR (300 MHz, DMSO-d 6 , $\delta$ ): 8.14-8.05 (m, 4H, ArH), 7.96-7.86 (m, 4H, ArH), 7.77 (d, 1H, J= 15.3 Hz, -CH=), $7.55(\mathrm{~d}, 2 \mathrm{H}, J=7.5 \mathrm{~Hz}, \mathrm{ArH}), 7.47$ (s, br, 1H, ArH), 7.03 (d, 4H, $J=8.4 \mathrm{~Hz}, \mathrm{ArH}), 6.91$ (d, 4H, J = 9.0 Hz, ArH), 6.78 $(\mathrm{d}, 2 \mathrm{H}, J=8.1 \mathrm{~Hz}, \mathrm{ArH}), 6.17(\mathrm{~d}, 1 \mathrm{H}, J=15.9 \mathrm{~Hz},-\mathrm{CH}=), 3.93\left(\mathrm{~s}, \mathrm{br}, 4 \mathrm{H},-\mathrm{OCH}_{2^{-}}\right), 2.75\left(\mathrm{~s}, \mathrm{br}, 2 \mathrm{H},-\mathrm{CH}_{2^{-}}\right), 1.70-1.61$ $\left(\mathrm{m}, 6 \mathrm{H},-\mathrm{CH}_{2}-\right), 1.40-1.31\left(\mathrm{~m}, 18 \mathrm{H},-\mathrm{CH}_{2}-\right), 0.90\left(\mathrm{~m}, 9 \mathrm{H},-\mathrm{CH}_{3}\right) .{ }^{13} \mathrm{C}$ NMR $\left(100 \mathrm{MHz}, \mathrm{THF}-d_{8}, \delta\right): 167.82,157.06$, $153.39,153.27,149.86,148.03,147.36,141.31,141.15,137.90,135.60,135.46,131.00,130.29,127.74,127.58$, $127.16,127.02,126.91,125.35,125.21,123.52,120.94,117.74,116.12,68.84,32.69,30.41,26.84,23.63,14.52$. HRMS (ESI, m/z): $[\mathrm{M}+\mathrm{H}]^{+}$calcd for: $\mathrm{C}_{53} \mathrm{H}_{59} \mathrm{~N}_{3} \mathrm{O}_{4} \mathrm{~S}_{3}$, 898.3745; Found, 898.3746. Anal. Cald for $\mathrm{C}_{53} \mathrm{H}_{59} \mathrm{~N}_{3} \mathrm{O}_{4} \mathrm{~S}_{3}: \mathrm{C}_{\text {, }}$ 70.87; H, 6.62; N, 4.68. Found: C, 70.65; H, 6.78; N, 4.77.

3-(4-(7-(5-(4-(bis(4-(hexyloxy)phenyl)amino)phenyl)thiophen-2-yl)benzo[c][1,2,5]thiadiazol-4-yl)phenyl)acrylic acid (LI-89)

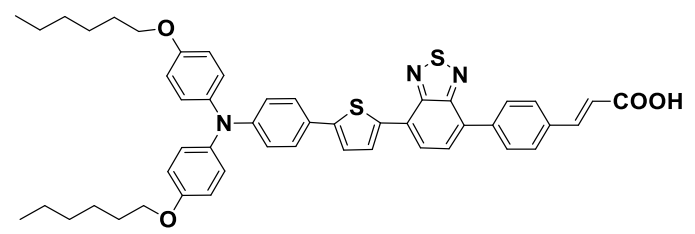

A dark red solid was obtained as the desired product (101 mg, 83.6\%).

${ }^{1} \mathrm{H}$ NMR (300 MHz, DMSO- $\left.d_{6}, \delta\right): 8.18-8.10(\mathrm{~m}, 4 \mathrm{H}, \mathrm{ArH}), 8.00(\mathrm{~d}, 1 \mathrm{H}, J=7.8 \mathrm{~Hz}, \mathrm{ArH}), 7.87(\mathrm{~d}, 2 \mathrm{H}, J=7.5 \mathrm{~Hz}$, ArH), $7.66(\mathrm{~d}, 1 \mathrm{H}, J=16.2 \mathrm{~Hz},=\mathrm{CH}-), 7.50(\mathrm{~s}, \mathrm{br}, 1 \mathrm{H}, \mathrm{ArH}), 7.06(\mathrm{~d}, 4 \mathrm{H}, J=8.4 \mathrm{~Hz}, \mathrm{ArH}), 6.93(\mathrm{~d}, 4 \mathrm{H}, J=8.7 \mathrm{~Hz}$, $\operatorname{ArH}), 6.80(\mathrm{~d}, 2 \mathrm{H}, J=8.1 \mathrm{~Hz}, \mathrm{ArH}), 6.63(\mathrm{~d}, 1 \mathrm{H}, J=16.5 \mathrm{~Hz},=\mathrm{CH}-), 3.94\left(\mathrm{t}, 4 \mathrm{H}, J=6.0 \mathrm{~Hz},-\mathrm{OCH}_{2^{-}}\right), 1.70(\mathrm{~m}, 4 \mathrm{H},-$ $\left.\mathrm{CH}_{2^{-}}\right), 1.42-1.32\left(\mathrm{~m}, 12 \mathrm{H},-\mathrm{CH}_{2^{-}}\right), 0.88\left(\mathrm{~s}, \mathrm{br}, 6 \mathrm{H},-\mathrm{CH}_{3}\right) .{ }^{13} \mathrm{C} \mathrm{NMR}\left(100 \mathrm{MHz}, \mathrm{THF}-d_{8}, \delta\right): 167.89,156.84,154.61$, $153.45,149.75,146.98,144.28,141.11,139.58,137.59,135.43,131.94,130.22,129.97,128.95,128.82,127.50$, 126.94, 126.82, 125.44, 123.27, 120.79, 119.88, 115.90, 68.62, 32.48, 30.51, 26.63, 23.42, 14.29. HRMS (ESI, m/z): 
$[\mathrm{M}+\mathrm{H}]^{+}$calcd for: $\mathrm{C}_{49} \mathrm{H}_{49} \mathrm{~N}_{3} \mathrm{O}_{4} \mathrm{~S}_{2}$, 808.3243; Found, 808.3246. Anal. Cald for $\mathrm{C}_{49} \mathrm{H}_{49} \mathrm{~N}_{3} \mathrm{O}_{4} \mathrm{~S}_{2}$ : C, 72.83; H, 6.11; N, 5.20;. Found: C, 72.73; H, 6.34; N, 5.19.

4-(7-(5-(4-(bis(4-(hexyloxy)phenyl)amino)phenyl)thiophen-2-yl)benzo[c][1,2,5]thiadiazol-4-yl)benzoic acid (LI-90)

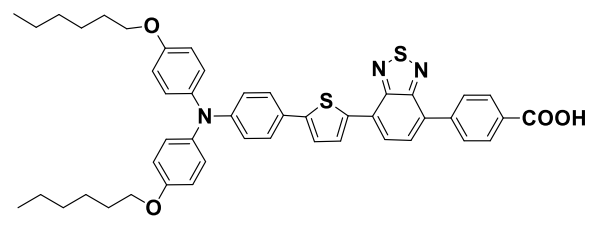

A dark red solid was obtained as the desired product (126 mg, 93.3\%).

${ }^{1} \mathrm{H}$ NMR $\left(300 \mathrm{MHz}, \mathrm{CDCl}_{3}+\mathrm{DMSO}-d_{6}, \delta\right): 8.23(\mathrm{~d}, 2 \mathrm{H}, J=7.8 \mathrm{~Hz}, \mathrm{ArH}), 8.15(\mathrm{~d}, 1 \mathrm{H}, J=3.9 \mathrm{~Hz}, \mathrm{ArH}), 8.00(\mathrm{~d}, 2 \mathrm{H}, J$ $=8.4 \mathrm{~Hz}, \operatorname{ArH}), 7.94(\mathrm{~d}, 1 \mathrm{H}, J=7.5 \mathrm{~Hz}, \mathrm{ArH}), 7.79(\mathrm{~d}, 1 \mathrm{H}, J=7.8 \mathrm{~Hz}, \mathrm{ArH}), 7.50(\mathrm{~d}, 2 \mathrm{H}, J=8.7 \mathrm{~Hz}, \mathrm{ArH}), 7.30$ (s, br, 1H, ArH), $7.08(\mathrm{~d}, 4 \mathrm{H}, J=8.4 \mathrm{~Hz}, \operatorname{ArH}), 6.94(\mathrm{~d}, 2 \mathrm{H}, J=8.1 \mathrm{~Hz}, \operatorname{ArH}), 6.85(\mathrm{~d}, 4 \mathrm{H}, J=9.0 \mathrm{~Hz}, \operatorname{ArH}), 3.95(\mathrm{t}, 4 \mathrm{H}, J=$ $\left.6.6 \mathrm{~Hz},-\mathrm{OCH}_{2^{-}}\right), 1.81\left(\mathrm{~m}, 4 \mathrm{H},-\mathrm{CH}_{2}-\right), 1.52-1.35\left(\mathrm{~m}, 12 \mathrm{H},-\mathrm{CH}_{2^{-}}\right), 0.91\left(\mathrm{t}, 6 \mathrm{H}, J=6.3 \mathrm{~Hz},-\mathrm{CH}_{3}\right) .{ }^{1} \mathrm{H} \mathrm{NMR}(100 \mathrm{MHz}$, $\left.\mathrm{CDCl}_{3}+\mathrm{DMSO}-d_{6}, \delta\right): 168.20,155.56,153.52,152.34,148.49,146.08,141.17,139.99,136.60,130.62,130.21,129.81$, $129.09,128.75,128.48,126.94,126.64,126.20,125.48,124.53,122.39,119.78,115.20,68.07,31.39,29.46,25.55$, 22.40, 13.87. HRMS (ESI, m/z): $[\mathrm{M}+\mathrm{H}]^{+}$calcd for: $\mathrm{C}_{49} \mathrm{H}_{51} \mathrm{~N}_{3} \mathrm{O}_{4} \mathrm{~S}_{2}$, 782.3086; Found, 782.3085. Anal. Cald for $\mathrm{C}_{47} \mathrm{H}_{47} \mathrm{~N}_{3} \mathrm{O}_{4} \mathrm{~S}_{2}:$ C, 72.19; H, 6.06; N, 5.37;. Found: C, 72.10; H, 6.21; N, 5.31.

2-(4-(7-(5-(4-(bis(4-(hexyloxy)phenyl)amino)phenyl)thiophen-2-yl)benzo[c] $[1,2,5]$ thiadiazol-4-yl)phenyl)acetic acid (LI-91)

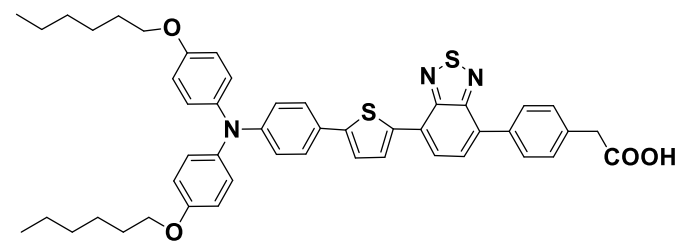

A dark red solid was obtained as the desired product (105 $\mathrm{mg}, 89.7 \%$ yield).

${ }^{1} \mathrm{H}$ NMR (300 MHz, DMSO- $\left.d_{6}, \delta\right): 8.12$ (m, 2H, ArH), 7.89 (m, 3H, ArH), 7.56 (d, 2H, $\left.J=8.4 \mathrm{~Hz}, \operatorname{ArH}\right), 7.44$ (m, $3 \mathrm{H}$, ArH), $7.04(\mathrm{~d}, 4 \mathrm{H}, J=8.7 \mathrm{~Hz}, \operatorname{ArH}), 6.91(\mathrm{~d}, 4 \mathrm{H}, J=8.7 \mathrm{~Hz}, \mathrm{ArH}), 6.79$ (d, 2H, $J=8.1 \mathrm{~Hz}, \mathrm{ArH}), 3.94$ (s, br, $4 \mathrm{H},-$ $\mathrm{OCH}_{2^{-}}$), $3.66\left(\mathrm{~s}, 2 \mathrm{H},-\mathrm{CH}_{2} \mathrm{COO}-\right), 1.69\left(\mathrm{~m}, 4 \mathrm{H},-\mathrm{CH}_{2^{-}}\right), 1.40-1.29\left(\mathrm{~m}, 12 \mathrm{H},-\mathrm{CH}_{2^{-}}\right), 0.87$ (s, br, $\left.6 \mathrm{H},-\mathrm{CH}_{3}\right) .{ }^{13} \mathrm{C} \mathrm{NMR}^{\mathrm{N}}$ $\left(100 \mathrm{MHz}, \mathrm{THF}-d_{8}, \delta\right): 177.41,155.58,153.83,152.51,148.50,145.89,140.25,136.98,136.26,133.40,131.52$, $129.59,129.27,128.87,127.96,126.93,126.70,126.45,126.38,125.86,124.83,122.54,120.13,115.45,68.19,40.99$, 
31.57, 29.65, 25.95, 22.76, 14.02. HRMS (ESI, m/z): $[\mathrm{M}+\mathrm{H}]^{+}$calcd for: $\mathrm{C}_{48} \mathrm{H}_{49} \mathrm{~N}_{3} \mathrm{O}_{4} \mathrm{~S}_{2}, 796.3243$; Found, 796.3249 . Anal. Cald for $\mathrm{C}_{48} \mathrm{H}_{49} \mathrm{~N}_{3} \mathrm{O}_{4} \mathrm{~S}_{2}:$ C, 72.42; H, 6.20; N, 5.28. Found: C, 72.27; H, 6.55; N, 5.35.

3-(4-(7-(5-(4-(bis(4-(hexyloxy)phenyl)amino)phenyl)thiophen-2-yl)benzo[c] $[1,2,5]$ thiadiazol-4yl)phenyl)propanoic acid (LI-92)

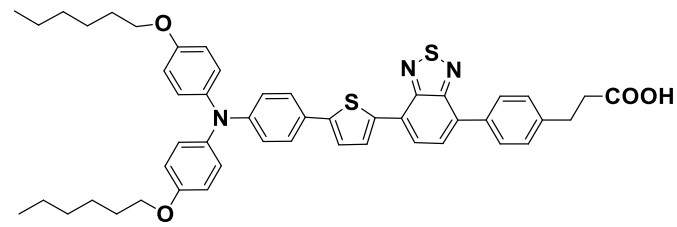

A dark red solid was obtained as the desired product (110 mg, 93.0\% yield).

${ }^{1} \mathrm{H}$ NMR (300 MHz, $\left.\mathrm{CDCl}_{3}, \delta\right): 8.11(\mathrm{~d}, 1 \mathrm{H}, J=3.3 \mathrm{~Hz}, \mathrm{ArH}), 7.89(\mathrm{~m}, 3 \mathrm{H}, \mathrm{ArH}), 7.70(\mathrm{~d}, 1 \mathrm{H}, J=7.5 \mathrm{~Hz}, \mathrm{ArH}), 7.50$ $(\mathrm{d}, 2 \mathrm{H}, J=8.7 \mathrm{~Hz}, \operatorname{ArH}), 7.40(\mathrm{~d}, 2 \mathrm{H}, J=7.2 \mathrm{~Hz}, \operatorname{ArH}), 7.26$ (s, br, 1H, ArH), $7.08(\mathrm{~d}, 4 \mathrm{H}, J=8.7 \mathrm{~Hz}, \operatorname{ArH}), 6.94(\mathrm{~d}$, $2 \mathrm{H}, J=8.1 \mathrm{~Hz}, \mathrm{ArH}), 6.84(\mathrm{~d}, 4 \mathrm{H}, J=8.7 \mathrm{~Hz}, \mathrm{ArH}), 3.94\left(\mathrm{t}, 4 \mathrm{H}, J=6.3 \mathrm{~Hz},-\mathrm{OCH}_{2^{-}}\right), 3.07\left(\mathrm{~s}, \mathrm{br}, 2 \mathrm{H},-\mathrm{CH}_{2^{-}}\right), 2.77(\mathrm{t}$, $\left.2 \mathrm{H}, J=7.2 \mathrm{~Hz},-\mathrm{CH}_{2^{-}}\right), 1.79\left(\mathrm{~m}, 4 \mathrm{H},-\mathrm{CH}_{2^{-}}\right), 1.47-1.34\left(\mathrm{~m}, 12 \mathrm{H},-\mathrm{CH}_{2^{-}}\right), 0.91\left(\mathrm{~s}, \mathrm{br}, 6 \mathrm{H},-\mathrm{CH}_{3}\right) .{ }^{13} \mathrm{C} \mathrm{NMR}(100 \mathrm{MHz}$, $\left.\mathrm{CDCl}_{3}, \delta\right): 179.03,155.59,153.88,152.54,148.50,145.80,140.26,137.05,135.36,131.76,129.22,128.83,128.48$ $127.81,126.87,126.70,126.37,126.27,125.88,124.89,122.53,120.14,115.26,68.20,35.61,31.58,30.33,29.29$, 25.73, 22.59, 14.04. HRMS (ESI, m/z): $[\mathrm{M}+\mathrm{H}]^{+}$calcd for: $\mathrm{C}_{49} \mathrm{H}_{51} \mathrm{~N}_{3} \mathrm{O}_{4} \mathrm{~S}_{2}, 810.3399$; Found, 810.3392. Anal. Cald for $\mathrm{C}_{49} \mathrm{H}_{51} \mathrm{~N}_{3} \mathrm{O}_{4} \mathrm{~S}_{2} \mathrm{C}, 72.65 ; \mathrm{H}, 6.35 ; \mathrm{N}, 5.19$. Found: C, 72.59; H, 6.51; N, 5.21.

(E)-3-(4-(7-(5-(4-(bis(4-(hexyloxy)phenyl)amino)phenyl)thiophen-2-yl)benzo[c] [1,2,5]thiadiazol-4-yl)-3,5dimethylphenyl)acrylic acid (LI-93)

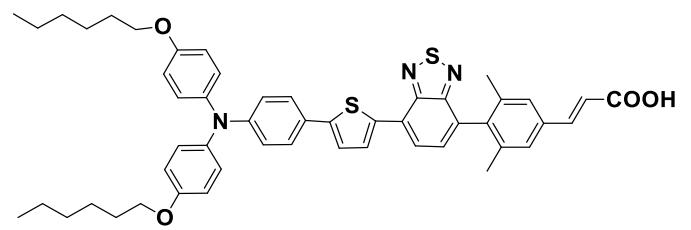

A red solid was obtained as the desired product (100 $\mathrm{mg}, 85.4 \%)$.

${ }^{1} \mathrm{H}$ NMR (300 MHz, DMSO- $\left.d_{6}, \delta\right): 8.16(\mathrm{~m}, 2 \mathrm{H}, \mathrm{ArH}), 7.62-7.49(\mathrm{~m}, 7 \mathrm{H}, \mathrm{ArH}$ and $-\mathrm{CH}=), 7.05(\mathrm{~d}, 4 \mathrm{H}, J=8.4 \mathrm{~Hz}$, ArH), $6.92(\mathrm{~d}, 4 \mathrm{H}, J=9.0 \mathrm{~Hz}, \mathrm{ArH}), 6.81(\mathrm{~d}, 2 \mathrm{H}, J=8.7 \mathrm{~Hz}, \mathrm{ArH}), 6.68(\mathrm{~d}, 1 \mathrm{H}, J=16.2 \mathrm{~Hz},=\mathrm{CH}-), 3.94(\mathrm{t}, 4 \mathrm{H}, J=$ $\left.6.3 \mathrm{~Hz},-\mathrm{OCH}_{2^{-}}\right), 1.95\left(\mathrm{~s}, 6 \mathrm{H},-\mathrm{CH}_{3}\right), 1.70\left(\mathrm{~m}, 4 \mathrm{H},-\mathrm{CH}_{2^{-}}\right), 1.41-1.30\left(\mathrm{~m}, 12 \mathrm{H},-\mathrm{CH}_{2^{-}}\right), 0.88\left(\mathrm{~s}, \mathrm{br}, 6 \mathrm{H},-\mathrm{CH}_{3}\right) .{ }^{13} \mathrm{C} \mathrm{NMR}^{-1}$ (100 MHz, THF- $\left.d_{8}, \delta\right): 168.07,157.00,155.42,153.14,149.82,146.87,145.01,141.31,140.15,138.23,138.02$, 
$135.38,132.87,130.86,130.13,128.01,127.73,127.65,127.14,126.98,125.45,123.46,121.06,119.64,116.11,68.81$, 32.65, 30.37, 26.81, 23.60, 20.82, 14.50. HRMS (ESI, m/z): $[\mathrm{M}+\mathrm{H}]^{+}$calcd for: $\mathrm{C}_{51} \mathrm{H}_{53} \mathrm{~N}_{3} \mathrm{O}_{4} \mathrm{~S}_{2}, 836.3556$; Found, 836.3559. Anal. Cald for $\mathrm{C}_{51} \mathrm{H}_{53} \mathrm{~N}_{3} \mathrm{O}_{4} \mathrm{~S}_{2}$ : C, 73.26; H, 6.39; N, 5.03. Found: C, 72.73; H, 6.34; N, 5.19.

4-(7-(5-(4-(bis(4-(hexyloxy)phenyl)amino)phenyl)thiophen-2-yl)benzo[c][1,2,5]thiadiazol-4-yl)-3,5dimethylbenzoic acid (LI-94)

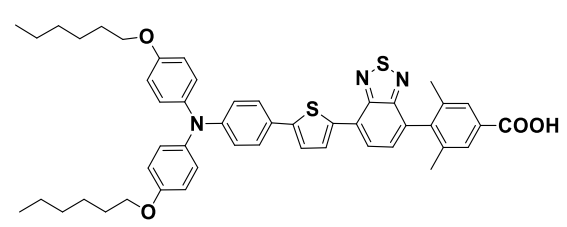

Compound 25 was used directly without further purification for hydrolysis. A dark red solid was obtained as the desired product ( $84 \mathrm{mg}, 61.0 \%)$.

${ }^{1} \mathrm{H}$ NMR (300 MHz, DMSO- $\left.d_{6}, \delta\right): 8.17$ (m, 2H, ArH), $7.78(\mathrm{~s}, 2 \mathrm{H}, \mathrm{ArH}), 7.55(\mathrm{~m}, 4 \mathrm{H}, \mathrm{ArH}), 7.05(\mathrm{~d}, 4 \mathrm{H}, J=8.4 \mathrm{~Hz}$ $\operatorname{ArH}), 6.92(\mathrm{~d}, 4 \mathrm{H}, J=8.4 \mathrm{~Hz}, \mathrm{ArH}), 6.81(\mathrm{~d}, 2 \mathrm{H}, J=8.1 \mathrm{~Hz}, \mathrm{ArH}), 3.94\left(\mathrm{t}, 4 \mathrm{H}, J=6.0 \mathrm{~Hz},-\mathrm{OCH}_{2^{-}}\right), 1.98(\mathrm{~s}, 6 \mathrm{H},-$ $\left.\mathrm{CH}_{3}\right), 1.70\left(\mathrm{~m}, 4 \mathrm{H},-\mathrm{CH}_{2^{-}}\right), 1.42-1.31\left(\mathrm{~m}, 12 \mathrm{H},-\mathrm{CH}_{2}-\right), 0.88\left(\mathrm{~s}, \mathrm{br}, 6 \mathrm{H},-\mathrm{CH}_{3}\right) .{ }^{13} \mathrm{C} \mathrm{NMR}\left(100 \mathrm{MHz}, \mathrm{CDCl}_{3}, \delta\right): 171.79$, $155.63,153.94,152.12,148.65,146.11,142.35,140.22,138.16,137.28,136.79,135.50,132.15,131.20,129.38$, $129.20,129.04,128.00,127.04,126.73,126.40,125.75,124.61,122.60,115.27,68.21,31.55,29.62,25.70,22.56$, 20.56, 13.99. HRMS (ESI, m/z): $[\mathrm{M}+\mathrm{H}]^{+}$calcd for: $\mathrm{C}_{49} \mathrm{H}_{51} \mathrm{~N}_{3} \mathrm{O}_{4} \mathrm{~S}_{2}$, 810.3399; Found, 810.3394. Anal. Cald for $\mathrm{C}_{49} \mathrm{H}_{51} \mathrm{~N}_{3} \mathrm{O}_{4} \mathrm{~S}_{2}:$ C, 72.65; H, 6.35; N, 5.19;. Found: C, 72.47; H, 6.55; N, 5.03.

\section{Cell fabrication}

DSCs were prepared following a modified literature procedure. ${ }^{17}$ Prior to the deposition of the $\mathrm{TiO}_{2}$ paste, the cleaned conducting glass substrates (FTO, $4 \mathrm{~mm}$ thickness, $\sim 9 \mathrm{ohms} / \mathrm{sq}$ ) were immersed in a solution of $\mathrm{TiCl}_{4}(40 \mathrm{mM})$ at $70{ }^{\circ} \mathrm{C}$ for $30 \mathrm{~min}$, washed with water and ethanol and then dried. The photoanodes (thickness $18 \mathrm{~mm}$; area $0.25 \mathrm{~cm}^{2}$ ) were prepared using the screen printing technique containing a $15 \mu \mathrm{m}$ layer of mesoporous $\mathrm{TiO}_{2}(18 \mathrm{NR}-\mathrm{T}$, Dyesol) and a 3 $\mu \mathrm{m}$ scatter layer (18NR-AO, Dyesol). The $\mathrm{TiO}_{2}$ electrodes were gradually heated under airflow at $325{ }^{\circ} \mathrm{C}$ for $5 \mathrm{~min}$, $375{ }^{\circ} \mathrm{C}$ for $5 \mathrm{~min}, 450{ }^{\circ} \mathrm{C}$ for $15 \mathrm{~min}$ and $500{ }^{\circ} \mathrm{C}$ for $1 \mathrm{~h}$. After the film was cooled to room temperature, they were immersed again in a solution of $\mathrm{TiCl}_{4}(40 \mathrm{mM})$ at $70{ }^{\circ} \mathrm{C}$ for $30 \mathrm{~min}$, washed with water and ethanol and then dried. The electrodes were annealed at $500{ }^{\circ} \mathrm{C}$ for $30 \mathrm{~min}$. After the $\mathrm{TiO}_{2}$ films were cooled to room temperature, they were quickly immersed in a $0.3 \mathrm{mM}$ dye solution with different solvent and maintained in dark for $18 \mathrm{~h}$ at room temperature. 
The sensitized electrodes were washed with corresponding solvent and dried in air. The counter electrodes were made by dropping a solution of $\mathrm{H}_{2} \mathrm{PtCl}_{6}$ in isopropyl alcohol $(10 \mathrm{mM}, 10 \mu \mathrm{L})$ onto a conducting glass substrate (FTO, 2.2 $\mathrm{mm}$ thickness, $9 \mathrm{ohms} / \mathrm{sq}, 1.25 \mathrm{~cm} \times 2.0 \mathrm{~cm}$ ) with two small holes to allow the injection of the liquid electrolyte. The solution was left to spread on glass substrates and then the glass substrates were heated to $400{ }^{\circ} \mathrm{C}$ for 30 min. For the assembly of DSCs, the sensitizer-covered $\mathrm{TiO}_{2}$ electrode and Pt-counter electrode were assembled into a sandwich type cell and sealed with a hot-melt gasket made of the ionomer Surlyn 1702 (DuPont, $25 \mu \mathrm{m}$ thickness). Finally, the hole was sealed with a Surlyn sheet (50 $\mu$ m thickness) and a thin glass cover by heating. The electrolyte consisted of $0.6 \mathrm{M}$ dimethylpropyl imidazolium iodide, $0.1 \mathrm{M}$ lithium iodide, $0.03 \mathrm{M}$ iodine, $0.5 \mathrm{M}$ tert-butylpyridine in Acetonitrile/3methoxypropionitrile $(1: 1, \mathrm{v} / \mathrm{v})$.

\section{DSCs characterization}

An AM 1.5 Solar Simulator (Model 94023A equipped with a 450W xenon arc lamp, Newport Co.) served as a light source. The light intensity was calibrated using a Si solar cell (Model 91150, Newport Co.) as a reference. $J$ - $V$ curves were obtained by applying an external bias to the cell and measuring the generated photocurrent with a Keithley model 2400 digital source meter. Incident photon-current conversion efficiency (IPCE) was recorded on a DC Power Meter (Model 2931-C equipped with a 300W xenon arc lamp, Newport Co.) under irradiation with a motorized monochromator (Oriel). The intensity modulated photovoltage spectroscopy (IMVS) and charge extraction method (CE) were measured by a Modulab XM PhotoEchem system with a white light emitting diode (LED) array using a previously reported method. ${ }^{18}$ The electrochemical impedance spectroscopy (EIS) was performed on complete cells in dark or under 0.5 sun under different potential biases with a frequency range of $0.1 \mathrm{~Hz}$ to $100 \mathrm{kHz}$ (Solartron Analytical). The potential bias interval was set to $25 \mathrm{mV}$. Obtained spectra were characterized using built-in software.

\section{Reference}

1. Zeng, W.; Cao, Y.; Bai, Y.; Wang, Y.; Shi, Y.; Zhang, M.; Wang, F.; Pan, C.; Wang, P. Efficient Dye-Sensitized Solar Cells with an Organic Photosensitizer Featuring Orderly Conjugated Ethylenedioxythiophene and Dithienosilole. Chem. Mater. 2010, 22, 1915-1925..

2. Zhou, N.; Prabakaran, K.; Lee, B.; Chang, S. H.; Harutyunyan, B.; Guo, P.; Butler, M. R.; Timalsina, A.; Bedzyk, M. J.; Ratner, M. A.; Vegiraju, S.; Yau, S.; Wu, C. G.; Chang, R. P.; Facchetti, A.; Chen, M. C.; Marks, T. J. MetalFree Tetrathienoacene Sensitizers for High-Performance Dye-Sensitized Solar Cells. J. Am. Chem. Soc. 2015, 137, 4414-4423.

3. Tsao, H. N.; Burschka, J.; Yi, C.; Kessler, F.; Nazeeruddin, M. K.; Grätzel, M. Influence of the Interfacial ChargeTransfer Resistance at the Counter Electrode in Dye-Sensitized Solar Cells Employing Cobalt Redox Shuttles. Energy Environ. Sci. 2011, 4, 4921-4924. 
4. Yang, J.; Ganesan, P.; Teuscher, J.; Moehl, T.; Kim, Y. J.; Yi, C.; Comte, P.; Pei, K.; Holcombe, T. W.; Nazeeruddin,

M. K.; Hua, J.; Zakeeruddin, S. M.; Tian, H.; Grätzel, M. Influence of the Donor Size in D- - -A Organic Dyes for Dye-Sensitized Solar Cells. J. Am. Chem. Soc. 2014, 136, 5722-5730.

5. Mathew, S.; Yella, A.; Gao, P.; Humphry-Baker, R.; Curchod, B. F.; Ashari-Astani, N.; Tavernelli, I.; Rothlisberger,

U.; Nazeeruddin, M. K.; Grätzel, M. Dye-Sensitized Solar Cells with 13\% Efficiency Achieved through the Molecular Engineering of Porphyrin Sensitizers. Nat. Chem. 2014, 6, 242-247.

6. Yao, Z.; Zhang, M.; Wu, H.; Yang, L.; Li, R.; Wang, P. Donor/Acceptor Indenoperylene Dye for Highly Efficient Organic Dye-Sensitized Solar Cells. J. Am. Chem. Soc. 2015, 137, 3799-3802.

7. Kakiage, K.; Aoyama, Y.; Yano, T.; Otsuka, T.; Kyomen, T.; Unno, M.; Hanaya, M. An Achievement of Over 12 Percent Efficiency in an Organic Dye-Sensitized Solar Cell. Chem. Commun. 2014, 50, 6379-6381.

8. Ito, S.; Miura, H.; Uchida, S.; Takata, M.; Sumioka, K.; Liska, P.; Comte, P.; Pechy, P.; Grätzel. M. HighConversion-Efficiency Organic Dye-Sensitized Solar Cells with a Novel Indoline Dye. Chem. Commun. 2008, 41, 5194-5196.

9. Haid, S.; Marszalek, M.; Mishra, A.; Wielopolski, M.; Teuscher, J.; Moser, J.-E.; Humphry-Baker, R.; Zakeeruddin, S. M.; Grätzel, M.; Bäuerle, P. Significant Improvement of Dye-Sensitized Solar Cell Performance by Small Structural Modification in $\pi$-Conjugated Donor-Acceptor Dyes. Adv. Funct. Mater. 2012, 22, 1291-1302.

10. Xiang, W.; Gupta, A.; Kashif, M. K.; Duffy, N.; Bilic, A.; Evans, R. A.; Spiccia, L.; Bach, U. Cyanomethylbenzoic Acid: an Acceptor for Donor- $\pi$-Acceptor Chromophores Used in Dye-Sensitized Solar Cells. ChemSusChem 2013, 6, 256-260.

11. Yella, A.; Mai, C. L.; Zakeeruddin, S. M.; Chang, S. N.; Hsieh, C. H.; Yeh, C. Y.; Grätzel, M. Molecular Engineering of Push-Pull Porphyrin Dyes for Highly Efficient Dye-sensitized Solar Cells: the Role of Benzene Spacers. Angew. Chem. Int. Ed. 2014, 53, 2973-2977.

12. Cabau, L.; Vijay Kumar, C.; Moncho, A.; Clifford, J. N.; López, N.; Palomares, E. A Single Atom Change "Switches-On" the Solar-to-Energy Conversion Efficiency of Zn-porphyrin Based Dye Sensitized Solar Cells to 10.5\%. Energy Environ. Sci. 2015, 8, 1368-1375.

13. Ganesan, P.; Yella, A.; Holcombe, T. W.; Gao, P.; Rajalingam, R.; Al-Muhtaseb, S. A.; Grätzel, M.; Nazeeruddin,

M. K. Unravel the Impact of Anchoring Groups on the Photovoltaic Performances of Diketopyrrolopyrrole Sensitizers for Dye-Sensitized Solar Cells. ACS Sustainable Chem. Eng. 2015, 3, 2389-2396.

14. Chai, Z.; Wu, M.; Fang, M.; Wan, S.; Xu, T.; Tang, R.; Xie, Y.; Mei, A.; Han, H.; Li, Q.; Li, Z. Similar or Totally Different: the Adjustment of the Twist Conformation Through Minor Structural Modification, and Dramatically Improved Performance for Dye-Sensitized Solar Cell. Adv. Energy Mater.2015, 5, 1500846. 
15. Grisdale, P. J.; Williams, J. L. R.; Glogowski, M. E.; Babb, B. E. Boron Photochemistry. VI. The Possible Role of Bridged Intermediates in the Photolysis of Borate Complexes. J. Org. Chem. 1971, 36, 544-549.

16. Chow, S. Y.; Williams, H. J.; Huang, Q.; Nanda, S.; Scott, A. I. Studies on Taxadiene Synthase: Interception of the Cyclization Cascade at the Isocembrene Stage with GGPP Analogues. J. Org. Chem. 2005, 70, 9997-10003.

17. Joly, D.; Pelleja, L.; Narbey, S.; Oswald, F.; Chiron, J.; Clifford, J. N.; Palomares, E.; Demadrille, R. A Robust Organic Dye for Dye Sensitized Solar Cells Based on Iodine/Iodide Electrolytes Combining High Efficiency and Outstanding Stability. Sci. Rep. 2014, 4, 4033.

18. Salim, N. T.; Yang, X.; Zhang, S.; Liu, J.; Islam, A.; Han, L. Shielding Effects of Additives in a Cobalt(II/III) Redox Electrolyte: toward Higher Open-Circuit Photovoltages in Dye-Sensitized Solar Cells. J. Mater. Chem. A 2014, 2, 10532-10539. 